\title{
Imaging Developmental and Interventional Plasticity Following Perinatal Stroke
}

\author{
Brandon T. Craig, Alicia Hilderley, Adam Kirton, Helen L. Carlson
}

\begin{abstract}
Perinatal stroke occurs around the time of birth and leads to lifelong neurological disabilities including hemiparetic cerebral palsy. Magnetic resonance imaging (MRI) has revolutionized our understanding of developmental neuroplasticity following early injury, quantifying volumetric, structural, functional, and metabolic compensatory changes after perinatal stroke. Such techniques can also be used to investigate how the brain responds to treatment (interventional neuroplasticity). Here, we review the current state of knowledge of how established and emerging neuroimaging modalities are informing neuroplasticity models in children with perinatal stroke. Specifically, we review structural imaging characterizing lesion characteristics and volumetrics, diffusion tensor imaging investigating white matter tracts and networks, task-based functional MRI for localizing function, resting state functional imaging for characterizing functional connectomes, and spectroscopy examining neurometabolic changes. Key challenges and exciting avenues for future investigations are also considered.
\end{abstract}

RÉSUMÉ : Recourir aux examens d'IRM pour mieux comprendre la plasticité développementale et interventionnelle à la suite d'un AVC périnatal. Les AVC périnataux vont survenir à peu près au moment de la naissance et entraîner des déficiences neurologiques à vie, par exemple une infirmité motrice cérébrale hémiparétique. Les examens d'IRM ont quant à eux révolutionné notre compréhension de la neuroplasticité développementale à la suite d'une lésion cérébrale survenue à un stade précoce. Ils permettent en effet de quantifier les changements compensatoires de nature volumique, structurelle, fonctionnelle et métabolique qui sont consécutifs à un AVC périnatal. De tels examens peuvent également être utilisés pour étudier la façon dont le cerveau réagit à un traitement (neuroplasticité interventionnelle). Nous voulons donc nous pencher ici sur l'état actuel de nos connaissances quant à la capacité des techniques de neuroimagerie, qu'elles soient établies ou émergentes, à nous renseigner au sujet des modèles de neuroplasticité chez des enfants victimes d'AVC périnataux. De manière plus spécifique, nous entendons passer en revue les résultats d'examens d'IRM ayant permis de caractériser l'étendue volumique et les lésions produites par ces AVC mais aussi des résultats basés sur la technique d'IRM de diffusion au sujet des sillons et des réseaux de la matière blanche, des résultats d'IRM fonctionnelle axée sur des tâches pour identifier les fonctions atteintes, des résultats d'IRM fonctionnelle à l'état de repos afin de caractériser les connectomes fonctionnels et des résultats spectroscopiques portant sur des changements d'ordre neurométabolique. Enfin, nous avons aussi tenu compte des défis clés et des avenues de recherche passionnantes pour le futur.

Keywords: Pediatric, MRI, Neuroimaging, Cerebral palsy, Resting state, Stroke

doi:10.1017/cjn.2020.166

Can J Neurol Sci. 2021; 48: 157-171

\section{INTRODUCTION}

Perinatal stroke causes hemiparetic cerebral palsy (HCP) and lifelong neurological disability. With morbidity spanning diverse aspects of a child's life and lasting for decades, global impact is large, including 10,000 Canadian children. The burden of disabilities will persist as pathophysiology is poorly understood and prevention strategies are non-existent. Limited treatments lead to loss of hope for children and families, necessitating exploration of new therapies.

As a focal injury in a healthy brain at the start of life, perinatal stroke represents an ideal model for the study of human developmental plasticity. Fortunately, combinations of preclinical and human studies are informing models of how the brain organizes specific functions after perinatal stroke. These models in turn are creating specific targets for neuromodulation where clinical trials are now underway. Advanced neuroimaging has been essential to this entire process, constructing the models to define individual patterns of developmental plasticity and then exploring the effects and potential mechanisms of intervention.
Here, we summarize the approaches, evidence, and emerging directions of how neuroimaging can inform our understanding of both developmental and interventional plasticity, paving the way for neuromodulation trials to improve outcomes for children with perinatal stroke.

\section{Perinatal Stroke: Disease States and Outcomes}

You will not incur a higher period of risk for ischemic stroke than the week you are born. ${ }^{1}$ A term newborn carries a risk

From the Calgary Pediatric Stroke Program, Alberta Children's Hospital, Calgary, AB, Canada (BTC, AH, AK, HLC); Hotchkiss Brain Institute, University of Calgary, Calgary, AB, Canada (BTC, AH, AK, HLC); Alberta Children's Hospital Research Institute (ACHRI), Calgary, AB, Canada (BTC, AH, AK, HLC); Department of Pediatrics, University of Calgary, Calgary, AB, Canada (HLC); Department of Clinical Neurosciences, University of Calgary, Calgary, AB, Canada (AK, AK); and Department of Radiology, University of Calgary, Calgary, AB, Canada (AK)

Received April 15, 2020. Final Revisions Submitted June 17, 2020. Date of AcCeptance July 23, 2020.

Correspondence to: Dr. Adam Kirton, Department of Pediatrics, Alberta Children's Hospital, 2888 Shaganappi Trail NW, Calgary, AB, Canada T3B 6A8. Email: Adam. kirton@ahs.ca 


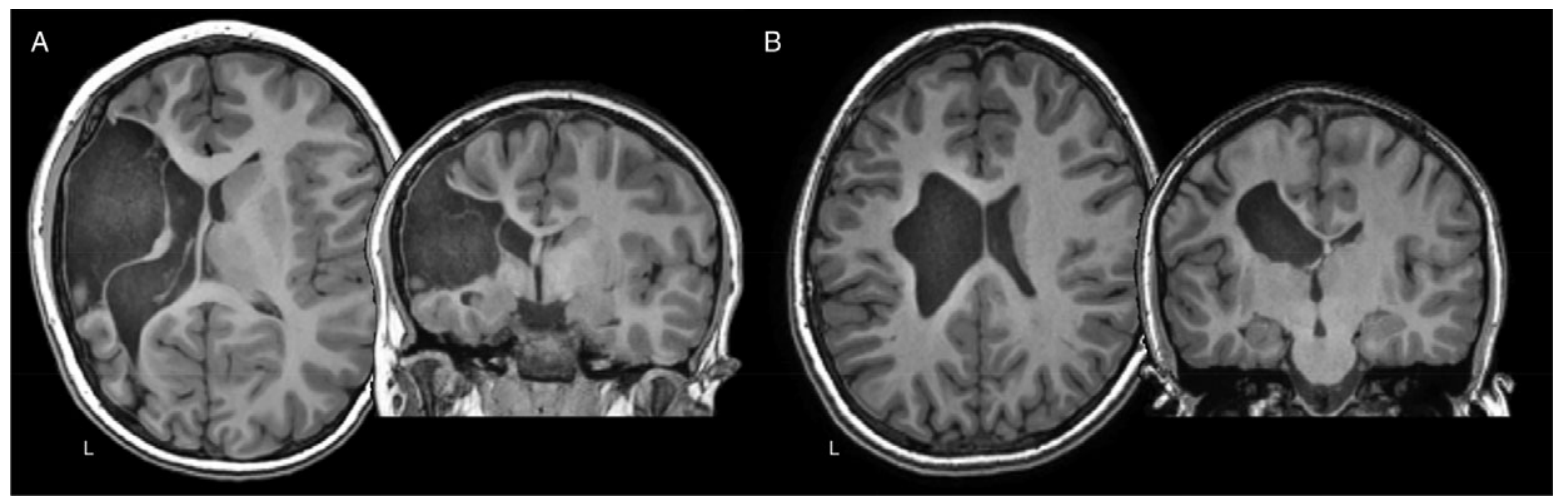

Figure 1: Axial and coronal T1-weighted anatomical images of two teenage children with left hemisphere perinatal strokes. (A) Arterial presumed perinatal ischemic stroke (APPIS). (B) Periventricular venous infarction (PVI). Both children have significant motor disabilities (hemiparetic cerebral palsy) that will last a lifetime.

$>1: 1500$, threefold higher than a week in the life of a diabetic, hypertensive, smoking adult and eightfold above all adults. ${ }^{2}$ An additional $50 \%$ of perinatal stroke presents later in infancy. ${ }^{3}$ Perinatal stroke is the leading cause of HCP and most survivors experience additional neurological comorbidities including intellectual disabilities, language impairments, developmental and behavioral disorders, and epilepsy. ${ }^{4,5}$ Frequent occurrence combined with lifelong morbidity generates a large global burden on affected children and their caregivers. Identification of a causative factor remains elusive in most $\operatorname{cases}^{1}$ and with no means of prevention, perinatal stroke will continue to impact the $>10,000$ affected Canadian children and their families for decades to come (Dunbar \& Kirton, under review).

An essential first step in improving outcomes from perinatal stroke is to understand the underlying disease. We have helped define distinct clinical-radiographic perinatal stroke syndromes using magnetic resonance imaging (MRI), ${ }^{6,7}$ refining perinatal stroke research toward specific disease states. Two main stroke types predominate (Figure 1). Arterial ischemic strokes (AISs) are large brain injuries secondary to occlusion of major cerebral arteries. Some present at birth with acute seizures (symptomatic neonatal AIS), while others are not recognized until infancy when hemiparesis becomes evident (arterial presumed perinatal ischemic stroke). ${ }^{7-9}$ In contrast, periventricular venous infarctions (PVIs) are subcortical white matter lesions acquired in the fetus before 34 weeks gestation, secondary to medullary venous infarction. ${ }^{7,10,11}$ MRI studies by our group and others have defined these fetal strokes, facilitating diagnosis. ${ }^{12,13} \mathrm{We}$ have validated this imaging-based classification system and demonstrated its research applications including MRI prediction of long-term outcomes, recognition of novel risk factors, MRI markers of pathophysiology, and new imaging targets for therapeutic interventions. ${ }^{7,9,14-18}$

Both AIS and PVI injure primary components of the motor system early in life, often resulting in HCP. Neurodevelopmental deficits occur in $\sim 75 \%$ of perinatal stroke survivors. ${ }^{4,5,19}$ Motor deficits are most prominent and are not limited to one body side. ${ }^{5,7,20-22}$ Ability to predict motor outcome early is limited, but MRI has dramatically improved the early identification of affected children, 7,19,20,23,24 including our use of diffusion MRI to predict hemiparesis. ${ }^{15,25,26}$ This has opened windows for earlier intervention. Deficits in language, vision, cognition, behavior, and epilepsy complicate $>50 \%$ of AIS with morbidities lasting a lifetime. Physical disability remains the main determinant of quality of life, and current interventions are limited. ${ }^{27,28}$

\section{Plastic Organization Following Perinatal Brain Injury}

The common features of unilateral, focal injury in an otherwise healthy brain, combined with distinct differences in lesion timing and location, make perinatal stroke an ideal human model for the study of developmental plasticity. ${ }^{29}$ In 1936, Kennard described better outcomes in younger primates following motor cortex lesions. ${ }^{30}$ This Kennard principle has fostered efforts to understand and harness age-related plasticity. Terms like "repair" and "reorganization" imply the existence of inherent restorative mechanisms that evolutionary models suggest do not exist. ${ }^{31}$ Instead, plastic adaptation represents ongoing developmental and compensatory processes occurring after injury.

Elegant animal work and human studies have solidified a model that increasingly explains motor function following early unilateral injury, creating novel avenues for therapeutic interventions. ${ }^{29,32-34}$ These will be outlined here to then demonstrate how advanced imaging has both informed progress and possesses new potential to expand our understanding.

\section{Synaptic Competition}

The targets of developing upper motor neuron systems are the spinal lower motor neurons, control of which appears to be a major determinant of clinical function. In typical development, ipsilateral and contralateral corticospinal tract (CST) projections arising from primary motor cortex (M1) are present in equal proportion at birth (Figure 2A). With continuous competition to establish synapses occurring through development, eventual contralateral domination results and ipsilateral projections have been shown to physically withdraw in animal models (Figure 2B). ${ }^{32,35,36}$ In humans, these connections are also thought to largely withdraw during the first 2 years of life, leaving few $(\sim 15 \%)$, slower conducting ipsilateral projections. ${ }^{32}$ Evidence from transcranial magnetic stimulation (TMS) studies in neurologically typical children (aged 8-18 years) are consistent and have found few detectible motor evoked responses in the ipsilateral hand. ${ }^{37}$ Continued motor practice during development 


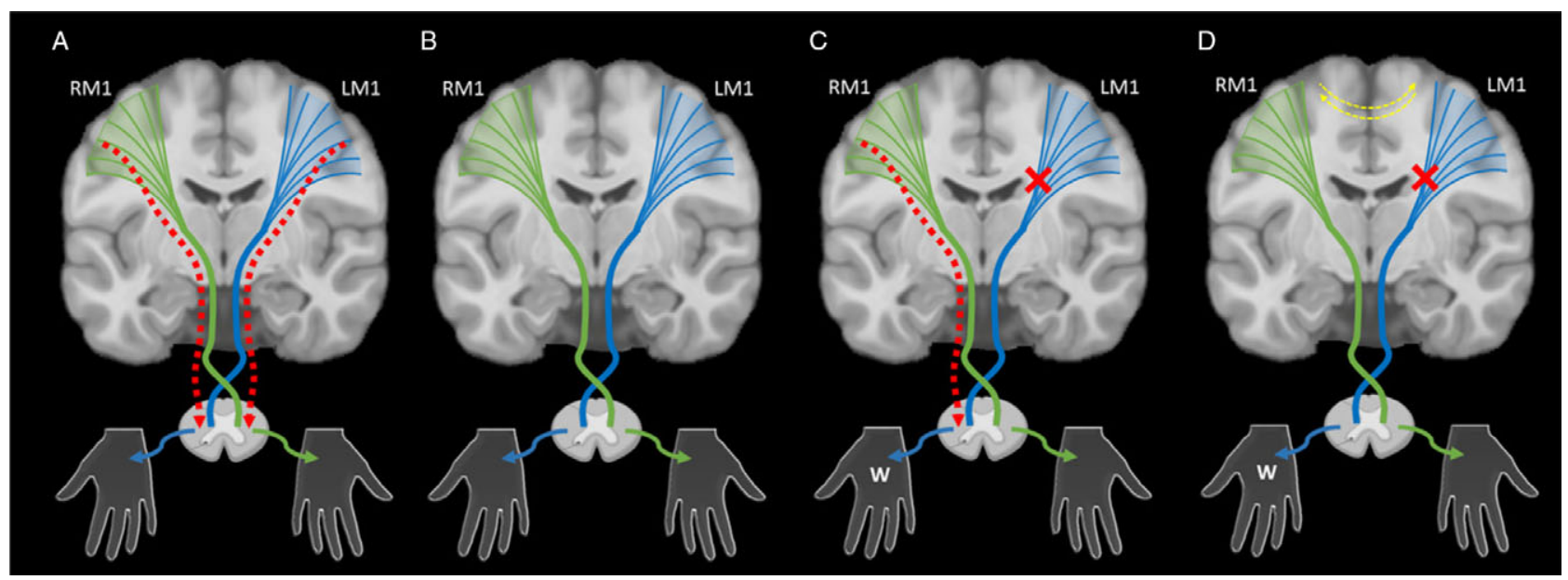

Figure 2: An illustration of the synaptic competition model. (A) In typical development, ipsilateral (red dashed lines) and contralateral corticospinal tract (CST) projections (green and blue lines) arising from primary motor cortex (M1) and broader cortical areas are present in equal proportion at birth. They compete with each other to establish synapses with lower motor neurons during early development. (B) With normal motor development, contralateral projections dominate and ipsilateral projections are withdrawn. (C) After an early unilateral injury such as perinatal stroke (red $x$ ), abnormal ipsilateral projections that would have been withdrawn may persist (red dashed line), resulting in ipsilateral (or bilateral) control of the weak hand (W), a pattern often associated with worse motor function. (D) Models suggest that intervention strategies focused on restoring typical contralateral organization of the motor system might maximize function. Adjuvant neuromodulation techniques may additionally influence this balance at multiple levels including the interhemispheric balance between primary motor cortices (yellow dashed lines). LM1 - left motor cortex, RM1 - right motor cortex.

strengthens contralateral connections, with plastic changes in M1 occurring in a use-dependent fashion. ${ }^{38,39}$

In the case of perinatal stroke, the injury reduces activity of sensorimotor neurons in the lesioned hemisphere resulting in a failure to maintain activity-dependent contralateral projections subsequently sparing ipsilateral projections. ${ }^{39}$ Resulting weakened contralateral competition from the lesioned hemisphere may cause ipsilateral projections that normally withdraw to persist resulting in ipsilateral (or bilateral) control of the weak hand and poorer motor function (Figure 2C).

\section{The Lesioned Hemisphere: Contralateral Projections to the Paretic Hand}

Adult stroke and animal studies suggest that retaining motor control in the lesioned hemisphere is associated with better physical function. ${ }^{40,41}$ This organization may be most efficacious because if relatively intact perilesional tissue mediates motor function in the paretic hand, existing (albeit damaged) contralateral CST projections are utilized which may be better suited to motor execution compared to weaker or "unintended" ipsilateral pathways. ${ }^{42} \mathrm{We}$ and others have correlated preserved contralateral projections with function. ${ }^{34,37}$ HCP studies show decreased excitability in the lesioned hemisphere with location of cortical activations approximating typical motor areas. ${ }^{43,44}$ Contralateral CST orientations also have better function in PVI. ${ }^{42}$ Small imaging studies suggest rehabilitation may increase lesioned motor cortex activations in $\mathrm{HCP} .{ }^{45,46}$ Enhancing motor control in the lesioned hemisphere may favor improved function but markers remain unestablished in perinatal stroke.

\section{The Contralesional Hemisphere: Ipsilateral Projections to the Paretic Hand}

Abnormal ipsilateral projections from the non-lesioned hemisphere to the paretic hand are common in HCP (Figure 2C). ${ }^{47-50}$
We and others have confirmed the association between this ipsilateral arrangement and poor function in perinatal stroke ${ }^{42,47-51}$. Importantly, over-activity of the contralesional M1 may be associated with larger deficits. ${ }^{42,50,52}$ In the largest TMS study of perinatal stroke $(n=52)$, we validated this neurophysiology of the contralesional M1. ${ }^{37}$

\section{Interhemispheric Dynamics}

Interhemispheric inhibition (IHI), whereby each hemisphere inhibits the other, may help to maintain excitatory and inhibitory balance in the motor system. ${ }^{53}$ IHI between the primary motor cortexes in school-aged children appears to be similar to that observed in adults. ${ }^{54}$ In perinatal stroke, we have shown that less IHI from the stroke to non-stroke M1 is associated with better function. ${ }^{55}$ Decreasing over-activity of contralesional M1 has been a commonly used approach to therapeutic neuromodulation in adult stroke. ${ }^{56,57}$ Such techniques may modulate cortical excitability to restore interhemispheric balance between the primary motor cortices (Figure 2D, yellow dashed lines) and thus represent a potential therapeutic target in HCP.

\section{Modulating Developmental Plasticity in Cerebral Palsy}

Interventional strategies may enhance contralateral (or inhibit ipsilateral) CST projections to improve physical function. There is strong animal evidence to support activity-dependent enhancement of contralateral CST connections. ${ }^{38,58}$ These findings complement evidence in human histopathological and neurophysiological studies including demonstration in healthy and injured newborns and infants. ${ }^{35,59,60}$ Leading interventional approaches for children with $\mathrm{HCP}$ build on evidence from adult stroke, namely manual therapies and non-invasive brain stimulation of cortical areas.

\section{Manual Therapy}

Manual therapies are designed to deliver motor learning-based therapy, the essential substrate for use-dependent plasticity. 
Limited use of the contralesional limb reduces opportunity for strengthening desirable contralateral CST connections, calling for therapies that focus on actively engaging children in intensive, repetitive, functional motor practice. The bulk of research to date has focused on constraint-induced movement therapy (CIMT). CIMT promotes use of an impaired limb by constraint of the lessimpaired limb, ${ }^{61}$ with multiple pediatric studies supporting CIMT effectiveness in HCP. ${ }^{62-65}$ In adult stroke, 2 weeks of CIMT can generate gains lasting years. ${ }^{66}$ Limitations of CIMT include a somewhat invasive nature and the exclusion of bimanual learning, which is arguably more useful for children's everyday life and may target sensorimotor deficits observed in function of both hands. ${ }^{67,68}$ Bimanual approaches provide interventional options that can also improve function in $\mathrm{HCP},{ }^{65,69}$ with comparable benefits to CIMT. Many programs now combine these methods. ${ }^{70}$ Response patterns vary with continued efforts to identify individual factors that may guide intervention selection. ${ }^{71}$

\section{Non-Invasive Brain Stimulation}

\section{Transcranial Magnetic Stimulation}

TMS uses electromagnetic induction to apply a suprathreshold pulse to focal cortical areas. TMS has high spatial resolution to affect discrete functional areas, offering non-invasive, painless mapping of motor systems. ${ }^{47,72-74}$ TMS neurophysiology procedures can quantify motor pathway integrity and cortical excitability ${ }^{75}$ and can elucidate interactions between different brain areas. Advances with TMS robotic measurements ${ }^{76}$ offer methods to assess dynamic changes in M1 that may occur following interventions. ${ }^{77}$ That non-invasive brain stimulation that can produce lasting changes in brain function is now well established. ${ }^{78}$ TMS is amenable to randomized, sham-controlled clinical trials with dozens in adult stroke demonstrating improved function. High-frequency repetitive pulse TMS (rTMS) stimulates cortex which both animal ${ }^{79-81}$ and human ${ }^{56}$ stroke studies can facilitate motor function. Low-frequency rTMS often reduces the excitability of the cerebral cortex ${ }^{82,83}$ and contralesional application may enhance stroke recovery in adults ${ }^{56}$ and hand function in $\mathrm{HCP},{ }^{84,85}$ with additive effects of CIMT and rTMS. ${ }^{86}$ Strong evidence supports rTMS safety in both adult and pediatric stroke trials including no adverse effects on hand function. ${ }^{56,85-89}$ Limitations of rTMS include burdensome, immobile hardware that prevents simultaneous rehabilitation.

\section{Transcranial Direct Current Stimulation}

Transcranial direct current stimulation (tDCS) applies simple scalp electrodes (anode and cathode) to generate weak currents (1-2 mA) that induce polarity-dependent changes ${ }^{90}$ and regional modulation of resting membrane potential and neuronal excitability. ${ }^{91}$ Anodal stimulation generally increases excitability, while cathodal stimulation decreases it but there are exceptions. ${ }^{92}$ tDCS safety and tolerability in adults ${ }^{93}$ and children ${ }^{89}$ are well established, and the portable nature of tDCS systems allows patient mobility during active rehabilitation, providing opportunity to potentially augment motor practice with concurrent neurostimulation. Motor cortex tDCS can enhance motor learning in animals, healthy adults and children, and adults with stroke during training. ${ }^{94-97}$ Investigations in children with HCP suggest benefit of combining tDCS with motor training. ${ }^{98,99}$ Use of tDCS and TMS seem promising, but mechanisms of action are not yet well understood.

Across intervention approaches, missing is an understanding of the underlying plastic changes that drive improvements in hand function following manual therapies and neuromodulation. This is required to identify individual factors that predict responsiveness to generate personalized neurorehabilitation to optimize function.

\section{NeUroimaging}

MRI affords incredible opportunities to explore how brain structure and function change as children with perinatal stroke grow (developmental plasticity) and to better understand the effects of training and neuromodulation (interventional plasticity). Application of advanced MRI techniques in perinatal stroke will allow us to further understand the brain's structure, function, and metabolism to identify individual markers with which to design targeted, personalized interventions. With the exciting advent of large publicly available imaging databases (including pediatric databases), future developments may establish large, normative comparison groups to further development of personalized neuroimaging biomarkers that can inform rehabilitation strategies in individual patients.

\section{Structural Imaging}

Perhaps the simplest method of imaging perinatal stroke is structural MRI. A standard T1- or T2-weighted anatomical image can provide a myriad of information regarding lesion location, character, and size as well as structural volumes, tissue signal intensity, thickness of cortical areas, and cortical complexity (i.e., gyrification or sulcal depth). Clinically obtained anatomical scans, including T2-weighted fluid-attenuated inversion recovery, often help classify the majority of stroke subtypes based on infarct shape, territory, and associated features. ${ }^{100}$

Historically, clinical brain lesion studies in adults have provided evidence of functional specificity. ${ }^{101,102}$ Advanced magnetic resonance (MR)-based lesion analysis techniques are now available such as voxel-based lesion symptom mapping ${ }^{103}$, lesionbehavior mapping ${ }^{104,105}$, lesion-network symptom-mapping, ${ }^{106}$ and most recently, connectome-based lesion-symptom mapping. ${ }^{107}$ Despite relatively simple acquisition and processing leading to powerful structure-function comparisons, studies using structural imaging in perinatal stroke are somewhat scarce. Frontal lesions typically associate with cognitive impairments, ${ }^{108}$ whereas damage to motor circuits (basal ganglia, M1) influence motor ability. ${ }^{109}$ Systematic lesion-symptom investigations in large numbers of perinatal stroke patients have not been reported thus far.

Volumetric analyses investigate differences in size of specific structures and the relation to clinical symptomology. Structures remote from, but connected to, the primary lesion have been shown to be altered by a process called diaschisis. ${ }^{110}$ Two recent studies in children with perinatal stroke have demonstrated smaller ipsilesional thalamic ${ }^{111}$ and contralesional cerebellar ${ }^{112}$ volumes compared to the opposing hemisphere. These findings were highly related to motor and cognitive function supporting the clinical relevance of volumetric investigations in both lesioned and nonlesioned hemispheres. Cortical volumes above subcortical PVI lesions have also been shown to be smaller though were not found to be associated with motor dysfunction. ${ }^{113}$ Volumetric studies thus 
provide converging evidence of neuroplastic changes occurring remotely from the original lesion that have clinical implications and may additionally shed light on changes in cortical volumes due to reorganization of function between hemispheres. More complex morphometry techniques investigating cortical thickness, gyrification, and sulcal depth quantify characteristics of gyri and sulci. ${ }^{114}$ While both of these methods have yet to be utilized in perinatal stroke, results in pediatric populations are promising. ${ }^{115,116}$

In addition to morphometric characteristics, image intensity of T1- and T2-weighted images can quantify underlying tissue composition. ${ }^{117,118}$ We have recently used this technique to explore potential alterations in myelination in perinatal stroke. ${ }^{119}$ Myelination, as estimated by $\mathrm{T} 1$ intensity, was decreased in perilesional areas compared to distal, intrahemispheric areas, and a contralesional homolog which itself had decreased intensity compared to age-matched controls. Additional methods of assessing myelination include taking a ratio of signal intensities between T1- and T2weighted images. ${ }^{120,121}$ This method may be effective in discerning myelination processes in white matter and gray matter areas in the very preterm ${ }^{122}$ but has yet to be explored in perinatal stroke.

\section{Diffusion Imaging}

One of the most impactful neuroimaging sequences used in both research and clinical settings is diffusion-weighted MRI (dw-MRI). The high sensitivity and specificity of dw-MRI for acute cerebral infarction make it the gold standard for clinical diagnosis of acute perinatal stroke. ${ }^{123-125}$ The cytotoxic edema that results from infarction leads to high signal intensity on the dw-MRI and a corresponding decrease in apparent diffusion coefficient or so-called "restricted diffusion". ${ }^{126-128}$ The clear visibility of acute infarcts on dw-MRI allows accurate diagnosis, early volume measurements, and informs clinical image scoring systems. ${ }^{129}$ Additionally, infarct location on dw-MRI can be helpful in estimating both mechanisms and prognosis. ${ }^{19,24,130}$

Early diffusion imaging can also demonstrate changes in areas anatomically connected to, but remote from, the primary stroke lesion via diaschisis. The extent of diffusion restriction along the CST tracts has been correlated with long-term motor outcome. ${ }^{15,131}$ Diffusion changes within specific locations may also be associated with functional outcomes, including visual and motor disability. ${ }^{132,133}$ Alterations in dw-MRI signal due to diaschisis is also measurable in highly connected structures remote from acute neonatal ischemic stroke, such as the thalamus and corpus callosum. ${ }^{134}$

More advanced diffusion imaging approaches may provide further insight into perinatal stroke plasticity. Diffusion tensor imaging (DTI) allows the estimation of diffusion properties within specific areas, structural tracts, and across the entire brain. ${ }^{135,136}$ Using region of interest and other approaches, specific structural tracts can be modeled using DTI tractography. Fractional anisotropy (FA) describes the unity of diffusion into equal directions (isotropic and decreased FA) or in specific directions (anisotropic and higher FA). Additional diffusion metrics from DTI approaches include axial diffusivity and radial diffusivity of each metric describing different characteristics and possible damage to underlying white matter (WM) microstructure. $^{137}$

White matter tract microstructure in children with perinatal stroke has been investigated using tractography, isolating specific tracts of interest and informing on sensorimotor network development following early brain injury. Differences in microstructure quantify potential alterations in underlying tract diffusion properties and structural connectivity. Lesioned side CST diffusion properties are often altered in perinatal stroke, the degree of which appears to correlate with motor deficits. ${ }^{138}$ A large, controlled study correlated CST diffusion properties with detailed robotic measures of motor function in hemiparetic children with perinatal stroke demonstrated differences between arterial and venous stroke populations. ${ }^{139}$ A similar robotic approach capable of measuring complex sensory functions such as proprioception and kinesthesia demonstrated correlations between these clinical functions and the diffusion properties of the dorsal column medial lemniscus tract. ${ }^{67}$ Future tractography approaches may explore broader components of sensorimotor (e.g., cortico-pontocerebellar) or more complex pathways mediating cognition. Further, tractography may also help to elucidate relative functional contributions of ipsilateral, contralateral, and interhemispheric pathways in models of developmental plasticity as described in the synaptic competition model above.

Tractography approaches can also be applied to the entire brain giving insight into global structural networks. Mathematical models such as graph theory can characterize pathways between regions and patterns of organization at the network level. ${ }^{140}$ Such structural white matter connectome methods that have been applied to more heterogenous cerebral palsy populations suggest that more ordered structural connectivity correlates with clinical function. ${ }^{141,142}$ Additionally, such structural connectome techniques may also quantify response to intervention, demonstrating improvements in clinical function following rehabilitation, ${ }^{143}$ suggesting possible utility in investigating interventional plasticity. We have recently confirmed that a structural connectomics approach is feasible in perinatal stroke. ${ }^{144}$ When investigating the non-lesioned hemisphere, we revealed modest but consistent relationships between baseline clinical motor function and some graph theory metrics. ${ }^{144}$

Advanced diffusion imaging methods may therefore open the door for investigating how structural and whole-brain connectivity change following intensive occupational therapy or noninvasive brain stimulation. Baseline microstructural variables in the lesioned CST correlated with larger gains in rehabilitation in children with unilateral cerebral palsy ${ }^{145}$ though results vary. ${ }^{146}$ Larger sample sizes with more stringent inclusion and exclusion criterion and robust, high-dose interventions capable of effecting clinical and functional change are needed in order to better understand how different forms of therapy are reflected in neuroimaging outcomes of brain plasticity. An additional translational application would be improving the ability to predict individual responsiveness to such interventions and more personalized neurorehabilitation.

Development of novel white matter diffusion techniques may facilitate such progress. Neurite orientation dispersion and density imaging (NODDI) quantifies microstructural complexities of dendrites and axons in vivo by calculating neurite density index and orientation dispersion index. ${ }^{147}$ These outcomes are sensitive to somas and glial cells that make up the extracellular space and the intraneurite space (between axons) thus quantifying angular variations of structure within a voxel characterizing white matter. NODDI has shown differences between lesioned and non-lesioned CSTs in children with unilateral cerebral palsy 
relating strongly to clinical function suggesting higher sensitivity for NODDI metrics (i.e., intracellular volume fraction) over traditionally used DTI metrics such as FA. ${ }^{148}$ Other emerging methods, such as myelin water fraction, quantitative inhomogeneous magnetization transfer, McDespot, and g-ratio, are all increasingly used in adults and may be translatable to pediatric populations. ${ }^{149-152}$ These methods may allow further investigation of the developmental neuroplasticity of structural connections following perinatal stroke and how such connections change or explain clinical behavior.

\section{Perfusion}

Brain perfusion can be quantified using techniques such as arterial spin labeling (ASL) giving insight into cerebral blood flow (CBF) after stroke. Traditionally, perfusion techniques have been used in acute clinical diagnosis of stroke and can visualize potentially salvageable tissue and disruptions in blood flow such as hyper-, hypoperfusion, and the diffusion-perfusion mismatch all of which may inform subsequent treatments. Currently, there is a paucity of evidence as to how differences in blood perfusion persist into chronic stages post-perinatal stroke and how this may relate to long-term function.

ASL is a non-contrast MRI technique that magnetically "labels" a bolus of blood in the carotid arteries before it enters the brain. After a brief post-labeling delay, the labeled blood is detectible as it perfuses the gray and white matter, and wholebrain quantitative maps estimating CBF can be calculated. Disruptions in perfusion in the central and peripheral regions of the infarct and changes in these disruptions over time have been investigated in a few studies of perinatal AIS patients near birth shortly after experiencing seizures. ${ }^{153-156}$ Although potentially informative in acute cases, longer-term developmental implications of such perfusion disruptions remain unclear. Given its noninvasive nature (i.e., no use of radioactive tracers such as in single-photon emission computed tomography ), ASL may be informative in future studies to investigate chronic differences in brain perfusion and development of perfusion-based biomarkers correlated with function.

\section{Functional MRI}

Functional MRI (fMRI) is distinct from, but complementary to, structural, diffusion, and perfusion MR sequences. The basis of fMRI is the blood-oxygen-level-dependent (BOLD) contrast which reflects changes in regional fluctuations in deoxyhemoglobin as a surrogate marker for underlying neuronal activity. As neural activity increases in a given brain area, demand for oxygen also increases leading to increased CBF to the area. Such neuralvascular coupling results in a hemodynamic response causing changes in relative oxy- and deoxyhemoglobin concentrations. Fluctuations in BOLD response over time can be measured during a task or at rest, giving rise to powerful techniques for investigating localization of function as well as intrinsic functional connectivity among different brain regions.

\section{Task-Based fMRI}

Task-based fMRI is very effective in localizing brain areas involved in execution of specific tasks. Commonly, participants perform a task interleaved with periods of rest. BOLD signal fluctuations are then compared across task and rest time courses, and resulting statistical maps (contrasting periods of rest with task) show "active" areas of statistically significant tasksynchronized changes in BOLD signal. These activation maps have high spatial resolution (at the $\mathrm{mm}$ level) for localization of areas of the brain actively recruited during specific tasks of interest and have been successful in characterizing patient-specific re-organization of functional areas after stroke in adults ${ }^{157-159}$ and injuries to the developing brain. ${ }^{160}$

\section{Resting-State fMRI}

Low-frequency BOLD fluctuations can also be assessed in the absence of a task (resting-state fMRI [RS-fMRI]) having the distinct advantage of being task-free and thus accessible to participants who cannot successfully complete specific tasks. Participants typically fixate on a cross and think about "nothing in particular". Since it is very unlikely for BOLD signal within multiple brain areas to significantly co-vary in time purely by chance, it is inferred that these areas are functionally connected. ${ }^{161}$ Higher temporal correlations of BOLD response are thus taken to represent higher functional connectivity.

Multiple reliable resting state networks have been identified, ${ }^{162}$ development and strengthening of such networks occurring across childhood and into early adulthood. The basic hubs for primary sensory functions (vision, audition, and sensorimotor) appear to develop very early, before birth. ${ }^{163}$ Throughout childhood, networks strengthen and follow a local-to-global pattern of development. ${ }^{164}$ Primary sensory networks appear first and are adult-like by around 8 years of age. ${ }^{165}$ The higher-level executive, attention, and default mode networks follow later in childhood and appear to keep developing into the teenage years. ${ }^{162}$

Analysis methods vary widely for RS-fMRI. Most commonly, methods assume that networks remain static in time. Seed-based analyses use regions of interest defined a priori based on anatomical atlases to define seeds for use in temporal crosscorrelation measurements. Independent component analysis (ICA) is another commonly used data-driven method that parcellates significantly co-varying voxels into resting-state networks from multivariate BOLD signals without using regions of interest or atlases. Analyzing RS-fMRI as dynamic data is a more advanced emerging approach that has yet to be applied in perinatal stroke.

\section{Sensorimotor Network}

The hand sensorimotor system has been investigated via task fMRI during active or passive finger tapping or hand-squeezing tasks. In typically developing children and adults, the pattern of activation during a unimanual hand task usually involves contralateral primary sensorimotor, premotor, supplementary motor, and posterior parietal cortices as well as the contralateral thalamus and basal ganglia, and ipsilateral cerebellum. Though activations typically follow a contralateral pattern, lesser bilateral activations may occur. ${ }^{166-168}$

After perinatal stroke, a comparison between paretic and lessaffected hand fMRI activation patterns may show one of three main patterns of re-organization in M1 that appear consistent with synaptic competition models. Ipsilesional re-organization reflects 


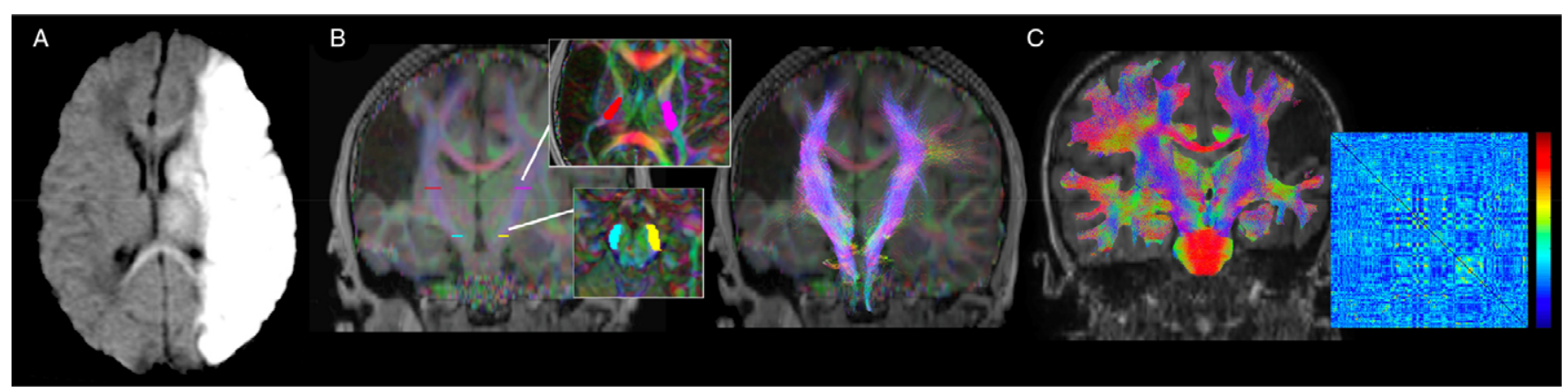

Figure 3: Diffusion imaging. (A) Restriction of water diffusion caused by an acute ischemic infarction on this axial diffusion image appears bright leading to accurate clinical diagnosis as well as identification of secondary diaschisis displaced from the primary lesion (genu, splenium, thalamus, and basal ganglia). (B) Diffusion tractography can isolate white matter bundles of interest such as the cortical spinal tract using known anatomy (posterior limb of the internal capsule and cerebral peduncles [inlays]) to guide region of interest placement. (C) Whole-brain tractography can quantify structural connectivity of wider brain networks.

recruitment of spared perilesional tissue to mediate sensorimotor tasks. ${ }^{42,51,169-174}$ Contralesional re-organization results from the shifting (or preservation) of motor function in the paretic limb to contralesional (ipsilateral) sensorimotor areas which may be associated with more extensive damage to the injured hemisphere. ${ }^{42,51,166-170,172}$ This reconfiguration results in ipsilateral cortex-mediating hand function (illustrated in Figure 2). More commonly, patients show a combination of both reorganization patterns (Figure 3) which results in bilateral representations of the paretic limb in both damaged and intact hemispheres. ${ }^{42,51,166,168,170,173,175,176}$ Bilateral activations seen on fMRI may also be due to sensorimotor feedback from unintended mirror movements rather than bilateral representations of the sensorimotor network itself. ${ }^{42,166,167,171,177}$ More systematic investigation and online monitoring of mirror movements may give insight into clinical manifestations of sensorimotor re-organization.

Evidence suggests that maintaining functional organization in ipsilesional areas is generally more effective in maximizing clinical motor function compared to the recruitment of contralateral or bilateral areas although considerable variability exists. ${ }^{42,159,172,177}$ Further demonstrations using active (primarily motor) and passive (primarily sensory) unimanual tasks show that hemispheric dissociation of motor and sensory functions results in the motor representation re-organizing into the non-lesioned hemisphere and the sensory representations remaining in the lesioned hemisphere. ${ }^{42,51,169}$ Such organization may be maladaptive and could lead to decreased motor function - even if the somatosensory projections of the sensory pathways can successfully divert around the lesion in the damaged hemisphere to reach their original cortical targets. ${ }^{178}$ Children who do have activations in the contralesional primary and secondary somatosensory cortices are likely to have poorer sensory function of their paretic hand. ${ }^{179}$ We do concede that for children with large lesions, ipsilesional reorganization may not be possible. In this situation, contralesional organization may be the only option and would not be maladaptive but rather necessary for preservation of residual function.

Many task fMRI studies investigate volume and peak height of activation areas during paretic hand sensorimotor tasks and have found that peaks are higher (i.e., higher statistical values $^{42,166,168}$ and the volume of activations are larger (i.e., more suprathreshold voxels) ${ }^{166-168}$ than for less-affected hand tasks or in comparison to controls. This commonly reported difference may be due to additional effort and wider cortical recruitment required to move the paretic hand. Height of activation peaks appear to be functionally relevant, ${ }_{166,170,177}$ and peak heights in the ipsilesional central sulcus are highly correlated with motor function. ${ }^{177}$ Ipsilateral parietal lobule and premotor cortex activations have also been linked to better performance on measures of dexterity in the paretic hand. ${ }^{166}$

Additional components of the sensorimotor network are likely altered and may include premotor, parietal, insular, superior temporal, and mesial frontal areas (supplementary and cingulate motor areas) as well as basal ganglia and cerebellum. ${ }^{42,166-168,172,175-177}$ In typical development, basal ganglia activations are usually contralateral given the rich connectivity with many sensorimotor cortical areas. ${ }^{180}$ In stroke patients with a contralesional (ipsilateral) re-organization pattern, activations in the basal ganglia also show reorganization to the contralesional side. ${ }^{180}$ Interestingly, the cerebellum shows bilateral recruitment after perinatal stroke, which may be a compensatory response to an effortful task ${ }^{168,175}$ as exclusively ipsilateral recruitment is commonly seen in healthy adults. ${ }^{168}$

Task fMRI can also be used to investigate interventional changes. CIMT-induced cortical reorganization may include a shift of motor control toward the lesioned hemisphere, but most studies have been in adult stroke. ${ }^{181-188}$ Small studies in HCP support possible alterations in lesioned M1 activity, ${ }^{45,46,189,190}$ with a predominant focus on M1 and limited exploration of network changes.

In typically developing children, resting-state sensorimotor networks are usually bilateral and symmetrical including somatosensory areas. ICA has demonstrated that children with AISs show trends toward lower sensorimotor system functional connectivity values compared to peers, but that children with PVI are not different from peers. ${ }^{191}$ A small study of children with HCP revealed unilateral, asymmetrical sensorimotor networks, with notable differences compared to typically developing peers in contralesional motor and supplementary motor areas. Differences were not related to lesion volume. ${ }^{192}$ Children with more lateralized motor networks responded better to CIMT, indicating that RS-fMRI may be a useful correlate with intervention response. ${ }^{192}$ Other ICA studies have shown absent or disrupted resting-state networks ${ }^{193}$ in HCP compared to peers, but detectable networks were stronger than peers and possibly spatially expanded to 


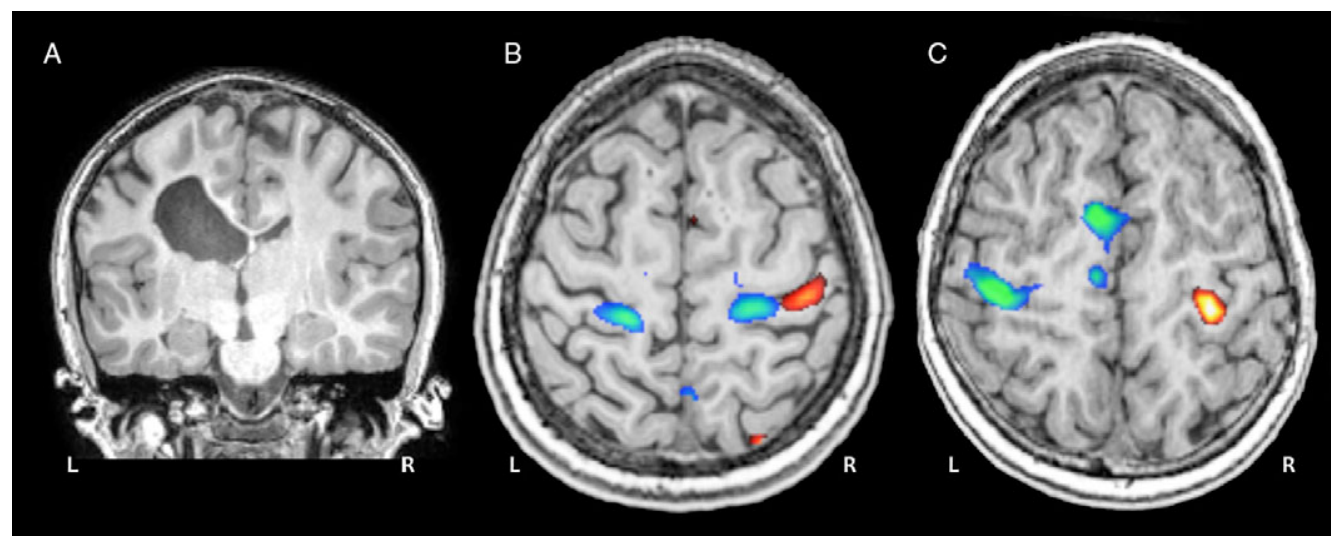

Figure 4: Motor task fMRI. (A) Coronal anatomical image of a 12-year-old child with a left periventricular venous infarction. (B) Task fMRI activation patterns during a ball squeeze task with the paretic (blue) and intact (red) hands show a bilateral re-organization pattern for the paretic hand. (C) Activation patterns for a typically developing control participant performing the same task with dominant (blue) and non-dominant (red) hands.

include other nearby cortical areas. ${ }^{194}$ A multimodal study in PVI suggested that differences in inter- and intrahemispheric functional connectivity may be CST-wiring specific. ${ }^{194}$

Seed-based analyses have indicated that AISs have significantly lower interhemispheric functional connectivity values in sensorimotor cortical regions than peers ${ }^{195,196}$ and that PVI show lower functional connectivity for supplementary motor areas compared to peers ${ }^{196}$ when seeding the lesioned M1. Higher intrahemispheric functional connectivity in the anterior supramarginal gyrus in the lesioned hemisphere of AIS was also observed compared to both typically developing peers and PVI. ${ }^{196}$ Alterations in resting-state sensorimotor networks within AIS and PVI groups did not seem to relate to motor function. ${ }^{191,197}$ In contrast, a recent study investigating PVI patients found functional connectivity within the sensorimotor network and the thalamus was associated with clinical motor and sensory function. $^{198}$

These RS-fMRI studies suggest that children with AIS have differences in network strength and topography compared to peers and that children with PVI seem to be more similar to peers. Relationships between functional connectivity and clinical motor/sensory function are inconsistent, possibly due to the heterogeneity of CST-wiring patterns. Future studies should continue to explore the role of the non-lesioned hemisphere as well as subcortical areas (i.e., thalamus and basal ganglia) as they may play an important role in sensorimotor system circuitry but have not been traditionally investigated in RS-fMRI studies.

\section{Language Network}

Uses of task fMRI and RS-fMRI are not limited to investigations of the sensorimotor network. The language network can be studied using fMRI tasks, such as verb generation, naming simple objects, saying words all starting with a certain letter, "word chains" in which the next word starts with the last letter of the preceding word, ${ }^{199}$ and story listening.

Language functions are significantly left hemisphere lateralized in most right-handed children, showing activations in anterior language areas such as left inferior frontal gyrus (i.e., Broca's area) during language production tasks. During language perception tasks, activations are typically more posterior in left superior temporal gyrus (i.e., Wernicke's area). This strong left laterality in typically developing participants develops over the course of development into early adulthood, with very young children usually showing bilateral organization. ${ }^{200}$ Additional areas recruited during language tasks include the basal ganglia, intraparietal sulcus, mesial frontal cortex, anterior cingulate, and superior/middle frontal gyrus. ${ }^{199,201,202}$

Similar to the sensorimotor system, there is a significant amount of re-organization in the language system occurring after perinatal stroke that can be examined using task fMRI. The most common re-organization patterns for the language network following a leftsided stroke are bilateral ${ }^{199,201-207}$ or contralesional with remapping to homologous areas in the right hemisphere. ${ }^{199,201-206,208}$ Retention of function in left hemisphere perilesional areas is relatively uncommon and may preferentially occur in those children with smaller lesions remote from primary language areas. $^{202,203}$ There is considerable between-patient variability in these patterns suggesting that lesion location ${ }^{203}$ and timing ${ }^{207}$ may play a role but apparently not lesion size. ${ }^{202,203,206,207}$

Language function in children with contralesional (right) or bilateral re-organization patterns is largely normal compared to peers, highlighting the potential for neuroplastic re-organization of extremely complex function after early injury. ${ }^{199,205,209}$ Children with bilateral activation patterns perform better than those with solely contra- or ipsilesional configurations. ${ }^{206}$ The locations of contralesional (right) peak activations after perinatal stroke appear to be quite precise right hemisphere homologs (i.e., mirror images) of left hemisphere activations in typically developing peers, ${ }^{199,201-203,205}$ with similar peak height ${ }^{199,202,203}$ and activation volume. ${ }^{202}$ Aphasia in these children is not common if the injury was very early in life, yet observed language performance differences may relate to activation patterns. ${ }^{205}$

It is unclear whether it is the innate equipotentiality of left and right hemispheres at birth that makes the language network so plastic, ${ }^{199}$ whether bilateral re-organization reflects incomplete re-mapping of language function to the contralesional (right) hemisphere, ${ }^{201}$ or is possibly a disinhibition of "dormant circuitry" available after early injury to interhemispheric inhibitory mechanisms. ${ }^{202}$ Irrespective of the underlying mechanism, emerging evidence indicates that language function in children after perinatal stroke is largely normal compared to peers 


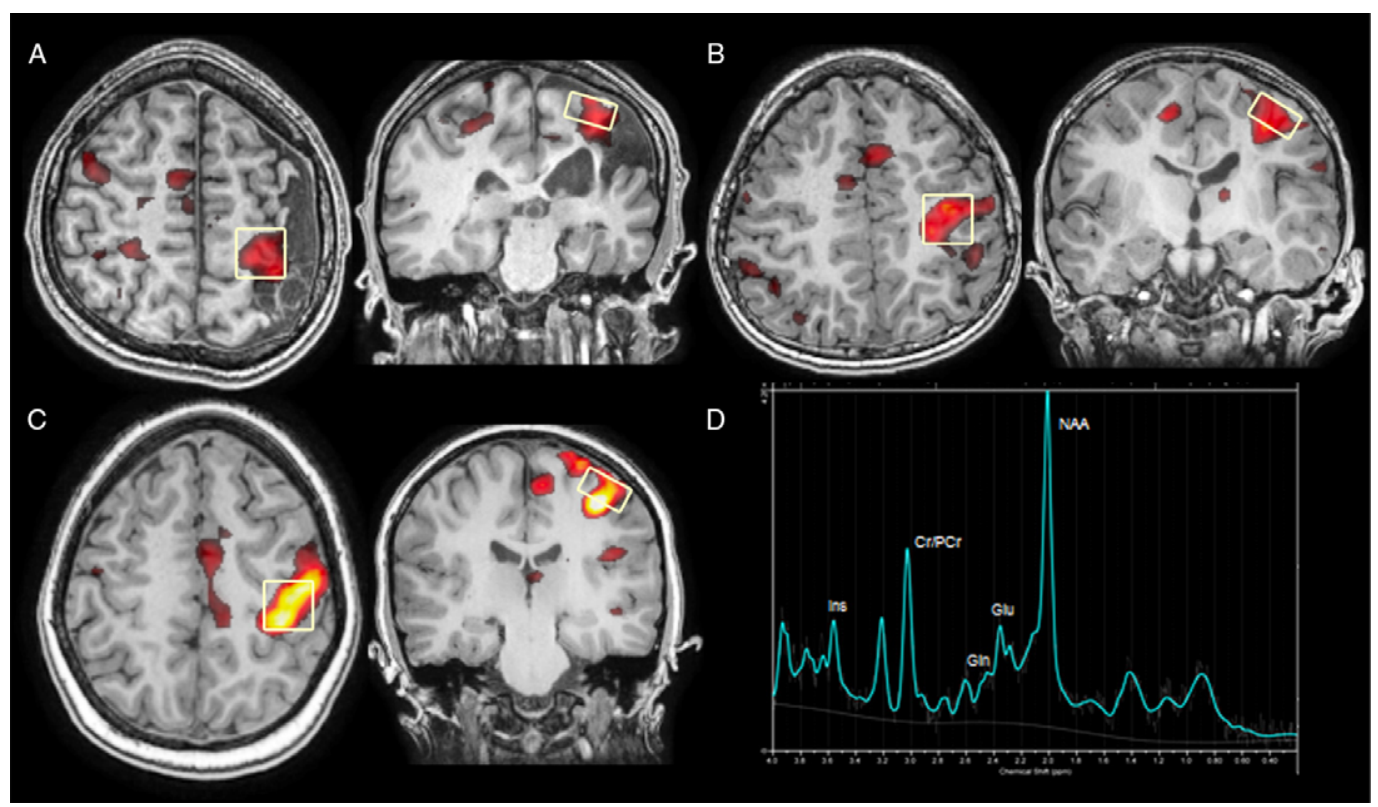

Figure 5: MR Spectroscopy. MRS voxel placements (yellow rectangles) guided by motor task fMRI activations for patients with (A) arterial ischemic stroke, (B) periventricular venous infarction, and (C) a typically developing control. (D) Resulting sample spectrum used to quantify neurometabolite concentrations within the MRS voxel reflecting underlying motor cortex neurochemistry. Adapted from Carlson et al., 2017.

highlighting the potential for neuroplastic re-organization of extremely complex function after early injury.

Use of RS-fMRI to explore language networks has been limited in perinatal stroke. Overall, children with stroke may have a disruption of resting-state networks and weaker interhemispheric functional connectivity as compared to peers, with region-specific differences in connectivity that appears highly related to language performance..$^{210,211}$

The bilateral symmetrical connectivity between left and right inferior frontal, superior temporal, and superior frontal gyri observed in typically developing children using seed-based analyses are not observed in children with left hemisphere stroke. ${ }^{211}$ These children have significant right laterality accompanied by lower functional connectivity in left inferior frontal gyrus, left middle temporal gyrus, left caudate nucleus, and left anterior thalamus. ${ }^{211}$ Intrahemispheric connectivity within the left hemisphere was highly correlated with language comprehension and verbal memory. ${ }^{211}$

During passive story listening, increased interhemispheric connectivity between right and left angular gyri was associated with poorer performance on a verbal comprehension test. ${ }^{210} \mathrm{By}$ contrast, increased functional connectivity between right and left superior temporal gyri was associated with better performance on multiple measures of receptive language for children with perinatal stroke but typically developing children showed the opposite pattern. Cerebellar interhemispheric connectivity was not related to function.

Since language is a very complex skill, patients may have unique compensatory mechanisms. Resting-state networks in children are also still developing, and more global (i.e., longer range) connectivity has not yet developed. These factors may underlie differences in findings. More RS-fMRI investigations are called for to better understand the development of language resting-state networks after perinatal stroke.

\section{Magnetic Resonance Spectroscopy}

Magnetic resonance spectroscopy (MRS) quantifies neurometabolite concentrations within a brain region of interest (i.e., an MRS voxel). Since each neurochemical of interest has a different molecular structure, they resonate at different MR frequencies and can be individually identified within an MRS spectrum (Figure 5). MRS analysis involves statistical modeling of a line of best fit to the spectrum thus measuring neurometabolite concentration within the voxel. Measuring metabolite concentrations provides information on neuronal health ( $\mathrm{N}$-acetyl-aspartate [NAA]), cell membrane turnover (choline compounds $[\mathrm{Cho}]=[\mathrm{GPC}+\mathrm{PCh}]$ ), energy metabolism (creatine compounds $[\mathrm{Cre}]=[\mathrm{Cr}+\mathrm{PCr}]$ ), metabolic activity and excitatory neurotransmitters (glutamate/glutamine $[\mathrm{Glx}])$, inhibitory neurotransmitters $(\gamma$-aminobutyric acid [GABA]), and health of glial cells (myo-Inositol [Ins]). ${ }^{212}$

MRS has not been widely used in perinatal stroke; however, meaningful comparisons have been made in the few studies to date. Lower concentrations of NAA, Cre, and Ins in the lesioned hemisphere motor cortex compared to the non-lesioned hemisphere were found in children with AIS. ${ }^{213}$ For children with PVI, hemispheric differences were found only for Cre. Children with spastic diplegia showed reductions in ratios of $\mathrm{Cre}$, Cho, and Ins to NAA in basal ganglia which was related to age, gender, ${ }^{214}$ and severity of disability. ${ }^{215}$ This suggests that differences in current neuronal health underlie hemispheric differences after perinatal stroke rather than differences in glutamate-related metabolic activity or excitability. Further, NAA and Cre concentrations were highly positively related to motor function on multiple clinical tasks, ${ }^{213}$ suggesting that MRS neurometabolites are stable biomarkers of brain health after perinatal stroke.

Predictable changes in neurometabolite concentrations following interventions have been documented using MRS in children with perinatal stroke. Reliable reductions in excitatory metabolite concentrations (Glx, Cre) were seen under the 
electrode after inhibitory tDCS compared to sham stimulation. ${ }^{216}$ Higher neurometabolite concentrations (NAA, Cho, Cre and Glx) at baseline were highly associated with better clinical motor function and a subset of these (Cre and Cho) were associated with subsequent response to intervention. ${ }^{216}$ Another brain stimulation trial using excitatory stimulation found increases in Glx: Cre ratio in M1 accompanied by increased NAA:Cre, Cho:Cre, and Ins:Cre ratios in the basal ganglia and concurrent improvements in spasticity of the affected limb. ${ }^{217}$

In summary, the findings that neurometabolite concentrations are highly associated with clinical motor function seem promising for defining a stable biomarker of neurochemistry that is quantifiable, relate highly to function, and change predictably with interventions. MRS-derived metabolite concentrations may also shed light on excitatory and inhibitory neurotransmitter concentrations informing models of synaptic competition and neuroplasticity (described above) at the level of neurochemistry. Advances in imaging technology are required to shorten MRS sequences, making it feasible to sample more voxels across cortical and subcortical areas.

\section{Challenges and Future Directions}

While the existing body of literature in imaging of HCP is impressive given the unique challenges this population provides, we can see several major challenges for neuroimaging in this population that could be resolved moving forward.

First, neuroimaging and neurophysiology studies to date in HCP have been underpowered and likely too simplistic to map complex interventional and developmental changes in M1 and across the motor network. Collaborative efforts among researchers studying HCP cohorts could overcome the issue of small sample sizes with ongoing multi-site studies leading the way.

Second, cutting-edge imaging techniques are challenging to adapt to a pediatric population given possibly long acquisition durations and/or task requirements. Children with perinatal stroke often have physical and cognitive disabilities introducing additional challenges with compliance and increased head motion associated with tasks. As new innovative sequences are made more efficient and developments in MR hardware improve acquisition times, HCP imaging research will benefit.

Third, adult brain atlases are not ideal for use with pediatric brains and automated tissue segmentation, coregistration, and normalization algorithms often struggle with large lesions. As preprocessing pipelines improve, possibly incorporating powerful machine learning techniques, these challenges may become more manageable.

Fourth, neuroimaging in HCP has traditionally focussed on single modalities. Converging evidence from multi-modal studies reflects the power of neuroimaging and non-invasive brain stimulation. For example, combining measures of neurophysiology (i.e., TMS), WM tractography, and task fMRI would provide a more comprehensive understanding of the re-organized sensorimotor system after perinatal stroke. ${ }^{37,42,171}$

Fifth, neuroimaging analysis techniques often utilize correlation estimates as outcomes, but this risks misinterpretation as causative or predictive relationships despite best practice recommendations. ${ }^{218}$ It is important that such misinterpretations are guarded against and appropriately predictive models should be pursued such as regression that are better able to elucidate possible causality in identifying biomarkers for brain-behavior relationships.

Sixth, non-invasive brain stimulation techniques such as TMS and tDCS are promising given their tolerability and apparent effectiveness in modulating cortical excitability leading to lasting improvements in motor function. Given that pairing brain stimulation with intensive rehabilitation may have additive effects compared to either technique alone, new hardware developments could focus on portability and miniaturization to facilitate this pairing, including in younger children. A recent example is transcranial static magnetic stimulation which we recently demonstrated is well tolerated and may modulate motor learning in children. ${ }^{219}$ Further, customizing TMS/tDCS dosage for each patient based on their individualized brain anatomy ${ }^{220-222}$ would effectively enhance personalized rehabilitation medicine.

Finally, as a field, we need to additionally focus not just on group statistics which may obscure important patient-specific nuances but move toward individualized patient neuroimaging biomarkers and comparisons with large normative databases of typically developing peers. By combining data from many imaging modalities and brain stimulation techniques, we can enhance our understanding of clinical function and neuroplasticity. Only by investigating individual imaging characteristics in each patient, we can use neuroimaging to enhance patientcentered interventional strategies.

\section{Conclusion}

Collectively, MRI modalities can be synergistically integrated to create comprehensive, in vivo models of brain structure and function to understand natural development and generate personalized maps of motor organization in children with perinatal stroke. Importantly, each method has also demonstrated the capacity to explore intervention-induced changes in brain function, bringing the potential to understand the mechanisms of therapy and neuromodulation in individual patients enhancing patient-centered personalized medicine after perinatal stroke.

\section{FUNDING}

BTC was supported by a Canadian Institute of Health Research (CIHR) Vanier Canadian Graduate Scholarship.

Program funding was provided by CIHR.

\section{Statement of Authorship}

BTC contributed to manuscript writing and editing. $\mathrm{AH}$ contributed to manuscript writing and editing. AK conceived and presented original idea and contributed to manuscript writing and editing. HLC contributed to manuscript writing and editing.

\section{REFERENCES}

1. Mineyko A, Kirton A. The black box of perinatal ischemic stroke pathogenesis. J Child Neurol. 2011;26(9):1154-62.

2. Petty GW, Brown RD Jr, Whisnant JP, et al. Ischemic stroke subtypes: a population-based study of incidence and risk factors. Stroke. 1999;30:2513-16.

3. Raju TN, Nelson KB, Ferriero D, Lynch JK. Ischemic perinatal stroke: summary of a workshop sponsored by the National Institute of Child Health and Human Development and the National Institute of Neurological Disorders and Stroke. Pediatrics. 2007;120:609-16. 
4. Sreenan C, Bhargava R, Robertson CM. Cerebral infarction in the term newborn: clinical presentation and long- term outcome. J Pediatr. 2000;137:351-55.

5. Kirton A. Life after perinatal stroke. Stroke. 2013;44(11):3265-71.

6. Kirton A, deVeber G. Advances in perinatal ischemic stroke. Pediatr Neurol. 2009;40:205-14.

7. Kirton A, deVeber G, Pontigon AM, MacGregor D, Shroff M. Presumed perinatal ischemic stroke: vascular classification predicts outcomes. Ann Neurol. 2008;63(4):436-43.

8. Golomb MR, MacGregor DL, Domi T, et al. Presumed pre- or perinatal arterial ischemic stroke: risk factors and outcomes. Ann Neurol. 2001;50:163-68.

9. Kirton A, Armstrong-Wells J, Chang T, et al. Symptomatic neonatal arterial ischemic stroke: the International Pediatric Stroke Study. Pediatrics. 2011;128(6):e1402-10.

10. Elchalal U, Yagel S, Gomori JM, et al. Fetal intracranial hemorrhage (fetal stroke): does grade matter? Ultrasound Obstet Gynecol. 2005;26:233-43.

11. Takanashi J, Barkovich AJ, Ferriero DM, Suzuki H, Kohno Y. Widening spectrum of congenital hemiplegia: periventricular venous infarction in term neonates. Neurology. 2003;61:531-33.

12. Kirton A, Wei X. Teaching neuroimages: confirmation of prenatal periventricular venous infarction with susceptibility-weighted MRI. Neurology. 2010;74(12):e48.

13. Takanashi J, Tada H, Barkovich AJ, Kohno Y. Magnetic resonance imaging confirms periventricular venous infarction in a term-born child with congenital hemiplegia. Dev Med Child Neurol. 2005; 47:706-8.

14. Domi T, deVeber G, Shroff M, et al. Corticospinal tract preWallerian degeneration: a novel outcome predictor for pediatric stroke on acute MRI. Stroke. 2009;40:780-87.

15. Kirton A, Domi T, Shroff M, Kouzmitcheva E, deVeber G. Acute descending corticospinal tract diffusion changes predict motor outcome and reorganization patterns in children with arterial ischemic stroke. Neurology. 2007;68(14):S48.

16. Tan M, Shroff M, Pontigon A, deVeber G, Kirton A. Role of occipital bone compression of the superior sagittal sinus in the pathophysiology of neonatal cerebral sinovenous thrombosis. Thromb Haemost. 2007;5(2):577.

17. Tuor UI, Qiao M, Morgunov M, et al. Magnetization transfer and diffusion imaging of acute axonal damage in the cerebral peduncle following hypoxia-ischemia in neonatal rats. Pediatr Res. 2013;73:325-31.

18. Tuor UI, Morgunov M, Sule M, et al. Cellular correlates of longitudinal diffusion tensor imaging of axonal degeneration following hypoxic-ischemic cerebral infarction in neonatal rats. NeuroImage Clin. 2014;6:32-42.

19. Mercuri E, Barnett A, Rutherford M, et al. Neonatal cerebral infarction and neuromotor outcome at school age. Pediatrics. 2004;113:95-100.

20. Lee J, Croen LA, Lindan C, et al. Predictors of outcome in perinatal arterial stroke: a population-based study. Ann Neurol. 2005;58(2):303-8.

21. Mercuri E, Jongmans $\mathrm{M}$, Bouza $\mathrm{H}$, et al. Congenital hemiplegia in children at school age: assessment of hand function in the nonhemiplegic hand and correlation with MRI. Neuropediatrics. 1999;30:8-13.

22. Trauner DA, Chase C, Walker P, Wulfeck B. Neurologic profiles of infants and children after perinatal stroke. Pediatr Neurol. 1993;9:383-86.

23. Boardman JP, Ganesan V, Rutherford MA, et al. Magnetic resonance image correlates of hemiparesis after neonatal and childhood middle cerebral artery stroke. Pediatrics. 2005;115:321-26.

24. Mercuri E, Rutherford M, Cowan F, et al. Early prognostic indicators of outcome in infants with neonatal cerebral infarction: a clinical, electroencephalogram, and magnetic resonance imaging study. Pediatrics. 1999;103:39-46.

25. De Vries LS, Van der Grond J, Van Haastert IC, Groenendaal F. Prediction of outcome in new-born infants with arterial ischaemic stroke using diffusion-weighted magnetic resonance imaging. Neuropediatrics. 2005;36(1):12-20.

26. van der Aa NE, Verhage $\mathrm{CH}$, Groenendaal $\mathrm{F}$, et al. Neonatal neuroimaging predicts recruitment of contralesional corticospinal tracts following perinatal brain injury. Dev Med Child Neurol. 2013;55(8):707-12.

27. Bemister TB, Brooks BL, Dyck RH, Kirton A. Parent and family impact of raising a child with perinatal stroke. BMC Pediatr. 2014;14:182.

28. Friefeld SJ, Westmacott R, MacGregor D, deVeber GA. Predictors of quality of life in pediatric survivors of arterial ischemic stroke and cerebral sinovenous thrombosis. J Child Neurol. 2011;26:1186-92.

29. Kirton A. Modeling developmental plasticity after perinatal stroke: defining central therapeutic targets in cerebral palsy. Pediatr Neurol. 2013;48(2):81-94.

30. Kennard MA. Age and other factors in motor recovery from precentral lesions in monkeys. Am J Physiol. 1936;115:137-46.

31. Trevathan WR. Introduction to evolutionary medicine. In: Trevathan WR, Smith EO, McKenna JJ, editors. Evolutionary medicine. New York: Oxford University Press Inc.; 1999, pp. 3-6.

32. Eyre JA. Corticospinal tract development and its plasticity after perinatal injury. Neurosci Biobehav Rev. 2007;31(8):1136-49.

33. Martin JH, Friel KM, Salimi I, Chakrabarty S. Activity- and usedependent plasticity of the developing corticospinal system. Neurosci Biobehav Rev. 2007;31(8):1125-35.

34. Staudt M. (Re-)organization of the developing human brain following periventricular white matter lesions. Neurosci Biobehav Rev. 2007;31(8):1150-56.

35. Eyre JA, Taylor JP, Villagra F, Smith M, Miller S. Evidence of activity-dependent withdrawal of corticospinal projections during human development. Neurology. 2001;57:1543-54.

36. Muller K, Kass-Iliyya F, Reitz M. Ontogeny of ipsilateral corticospinal projections: a developmental study with transcranial magnetic stimulation. Ann Neurol. 1997;42:705-11.

37. Zewdie E, Damji O, Ciechanski P, Seeger T, Kirton A. Contralesional corticomotor neurophysiology in hemiparetic children with perinatal stroke: developmental plasticity and clinical function. Neurorehabil Neural Repair. 2016;31(3):261-71.

38. Salimi I, Martin JH. Rescuing transient corticospinal terminations and promoting growth with corticospinal stimulation in kittens. J Neurosci. 2004;24:4952-61.

39. Martin JH, Lee SJ. Activity-dependent competition between developing corticospinal terminations. Neuroreport. 1999;10:2277-82.

40. Ward NS. Functional reorganization of the cerebral motor system after stroke. Curr Opin Neurol. 2004;17:725-30.

41. Werhahn KJ, Conforto AB, Kadom N, Hallett M, Cohen LG. Contribution of the ipsilateral motor cortex to recovery after chronic stroke. Ann Neurol. 2003;54:464-72.

42. Staudt M, Grodd W, Gerloff C, et al. Two types of ipsilateral reorganization in congenital hemiparesis: a TMS and fMRI study. Brain. 2002;125:2222-37.

43. Berweck S, Walther M, Brodbeck V, et al. Abnormal motor cortex excitability in congenital stroke. Pediatr Res. 2008;63:84-8.

44. Staudt M, Gerloff C, Grodd W, et al. Reorganization in congenital hemiparesis acquired at different gestational ages. Ann Neurol. 2004;56:854-63.

45. Juenger $H$, Linder-Lucht $M$, Walther $M$, et al. Cortical neuromodulation by constraint-induced movement therapy in congenital hemiparesis: an FMRI study. Neuropediatrics. 2007;38:130-36.

46. Walther M, Juenger $\mathrm{H}$, Kuhnke N, et al. Motor cortex plasticity in ischemic perinatal stroke: a transcranial magnetic stimulation and functional MRI study. Pediatr Neurol. 2009;41(3):171-78.

47. Carr LJ, Harrison LM, Evans AL, Stephens JA. Patterns of central motor reorganization in hemiplegic cerebral palsy. Brain. 1993;116 (Pt 5):1223-47.

48. Farmer SF, Harrison LM, Ingram DA, Stephens JA. Plasticity of central motor pathways in children with hemiplegic cerebral palsy. Neurology. 1991;41:1505-10.

49. Maegaki Y, Maeoka Y, Ishii S, et al. Mechanisms of central motor reorganization in pediatric hemiplegic patients. Neuropediatrics. 1997;28:168-74.

50. Nezu A, Kimura S, Takeshita S, Tanaka M. Functional recovery in hemiplegic cerebral palsy: ipsilateral electromyographic responses to focal transcranial magnetic stimulation. Brain Dev. 1999;21:162-65. 
51. Thickbroom GW, Byrnes ML, Archer SA, Nagarajan L, Mastaglia FL. Differences in sensory and motor cortical organization following brain injury early in life. Ann Neurol. 2001;49:320-27.

52. Ragazzoni A, Cincotta M, Borgheresi A, Zaccara G, Ziemann U. Congenital hemiparesis: different functional reorganization of somatosensory and motor pathways. Clin Neurophysiol. 2002;113:1273-78.

53. Ferbert A, Priori A, Rothwell JC, et al. Interhemispheric inhibition of the human motor cortex. J Physiol. 1992;453:525-46.

54. Ciechanski P, Zewdie E, Kirton A. Developmental profile of motor cortex transcallosal inhibition in children and adolescents. J Neurophysiol. 2017;118(1):140-48.

55. Eng D, Zewdie E, Ciechanski P, Damji O, Kirton A. Interhemispheric motor interactions in hemiparetic children with perinatal stroke: clinical correlates and effects of neuromodulation therapy. Clin Neurophysiol. 2018;129(2):397-405.

56. Hsu WY, Cheng CH, Liao KK, Lee IH, Lin YY. Effects of repetitive transcranial magnetic stimulation on motor functions in patients with stroke: a meta-analysis. Stroke. 2012;43(7):1849-57.

57. Kang N, Summers JJ, Cauraugh JH. Transcranial direct current stimulation facilitates motor learning post-stroke: a systematic review and meta-analysis. J Neurol Neurosurg Psychiatry. 2016;87(4):345-55.

58. Grefkes C, Fink GR. Reorganization of cerebral networks after stroke: new insights from neuroimaging with connectivity approaches. Brain. 2011;134:1264-76.

59. Martin JH, Kably B, Hacking A. Activity-dependent development of cortical axon terminations in the spinal cord and brain stem. Exp Brain Res. 1999;125:184-99.

60. Scales DA, Collins GH. Cerebral degeneration with hypertrophy of the contralateral pyramid. Arch Neurol. 1972;26:186-90.

61. Taub E, Crago JE, Uswatte G. Constraint-induced movement therapy: a new approach to treatment in physical rehabilitation. Rehabil Psychol. 1998;43(2):152-70.

62. Eliasson AC, Krumlinde-Sundholm L, Shaw K, Wang C. Effects of constraint-induced movement therapy in young children with hemiplegic cerebral palsy: an adapted model. Dev Med Child Neurol. 2005;47(4):266-75.

63. Taub E, Ramey SL, DeLuca S, Echols K. Efficacy of constraintinduced movement therapy for children with cerebral palsy with asymmetric motor impairment. Pediatrics. 2004;113:305-12.

64. Willis JK, Morello A, Davie A, Rice JC, Bennett JT. Forced use treatment of childhood hemiparesis. Pediatrics. 2002;110:94-6.

65. Novak I, Morgan C, Fahey M, et al. State of the evidence traffic lights 2019: systematic review of interventions for preventing and treating children with cerebral palsy. Curr Neurol Neurosci Rep. 2020;20(2):3.

66. Wolf SL, Winstein CJ, Miller JP, et al. Retention of upper limb function in stroke survivors who have received constraint-induced movement therapy: the EXCITE randomised trial. Lancet Neurol. 2008;7(1):33-40.

67. Kuczynski AM, Carlson HL, Lebel C, et al. Sensory tractography and robot-quantified proprioception in hemiparetic children with perinatal stroke. Hum Brain Mapp. 2017;38(5):2424-40.

68. Rich TL, Menk JS, Rudser KD, Feyma T, Gillick BT. Lessaffected hand function in children with hemiparetic unilateral cerebral palsy: a comparison study with typically developing peers. Neurorehabil Neural Repair. 2017;31(10-11):965-76.

69. Gordon AM, Schneider JA, Chinnan A, Charles JR. Efficacy of a hand-arm bimanual intensive therapy (HABIT) in children with hemiplegic cerebral palsy: a randomized control trial. Dev Med Child Neurol. 2007;49(11):830-38.

70. Gordon AM, Hung YC, Brandao M, et al. Bimanual training and constraint-induced movement therapy in children with hemiplegic cerebral palsy: a randomized trial. Neurorehabil Neural Repair. 2011;25(8):692-702.

71. Schertz M, Shiran SI, Myers V, et al. Imaging predictors of improvement from a motor learning-based intervention for children with unilateral cerebral palsy. Neurorehabil Neural Repair. 2016;30(7):647-60.

72. Garvey MA, Gilbert DL. Transcranial magnetic stimulation in children. Eur J Paediatr Neurol. 2004;8:7-19.
73. Kirton A, deVeber G, Gunraj C, Chen R. Cortical excitability and interhemispheric inhibition after subcortical pediatric stroke: plastic organization and effects of rTMS. Clin Neurophysiol. 2010;121:1922-29.

74. Rajapakse T, Kirton A. Non-invasive brain stimulation in children: applications and future directions. Transl Neurosci. 2013;4(2). doi: 10.2478/s13380-013-0116-3

75. Zewdie E, Kirton A. TMS basics: single and paired pulse neurophysiology. In: Kirton A, Gilbert DL, editors. Pediatric brain stimulation: mapping and modulating the developing brain. Amsterdam: Elsevier; 2016, p. 475.

76. Ginhoux R, Renaud P, Zorn L, et al. A custom robot for Transcranial Magnetic Stimulation: first assessment on healthy subjects. Conf Proc IEEE Eng Med Biol Soc. 2013;2013:5352-55.

77. Friel KM, Kuo H-C, Fuller J, et al. Skilled bimanual training drives motor cortex plasticity in children with unilateral cerebral palsy. Neurorehabil Neural Repair. 2016;30(9):834-44.

78. Lefaucheur J-P, André-Obadia N, Antal A, et al. Evidence-based guidelines on the therapeutic use of repetitive transcranial magnetic stimulation (rTMS). Clin Neurophysiol. 2014;125(11): 2150-206.

79. Adkins-Muir DL, Jones TA. Cortical electrical stimulation combined with rehabilitative training: enhanced functional recovery and dendritic plasticity following focal cortical ischemia in rats. Neurol Res. 2003;25:780-88.

80. Kleim JA, Bruneau R, VandenBerg P, et al. Motor cortex stimulation enhances motor recovery and reduces peri-infarct dysfunction following ischemic insult. Neurol Res. 2003;25: 789-93.

81. Teskey GC, Flynn C, Goertzen CD, Monfils MH, Young NA. Cortical stimulation improves skilled forelimb use following a focal ischemic infarct in the rat. Neurol Res. 2003;25:794-800.

82. Chen R, Classen J, Gerloff C, et al. Depression of motor cortex excitability by low-frequency transcranial magnetic stimulation. Neurology. 1997;48:1398-403.

83. Pascual-Leone A, Amedi A, Fregni F, Merabet LB. The plastic human brain cortex. Annu Rev Neurosci. 2005;28:377-401.

84. Kirton A, Chen R, Friefeld S, et al. Contralesional repetitive transcranial magnetic stimulation for chronic hemiparesis in subcortical paediatric stroke: a randomised trial. Lancet Neurol. 2008;7(6):507-13.

85. Gillick BT, Krach LE, Feyma T, et al. Primed low-frequency repetitive transcranial magnetic stimulation and constraint-induced movement therapy in pediatric hemiparesis: a randomized controlled trial. Dev Med Child Neurol. 2014;56(1):44-52.

86. Kirton A, Andersen J, Herrero M, et al. Brain stimulation and constraint for perinatal stroke hemiparesis: the Plastic Champs Trial. Neurology. 2016;86(18):1659-67.

87. Friel KM, Gordon AM, Carmel JB, Kirton A, Gillick BT. Pediatric issues in neuromodulation: safety, tolerability and ethical considerations. In: Kirton A, Gilbert DL, editors. Pediatric brain stimulation: mapping and modulating the developing brain. Amsterdam: Elsevier; 2016, p. 475.

88. Wassermann EM. Risk and safety of repetitive transcranial magnetic stimulation: report and suggested guidelines from the International Workshop on the Safety of Repetitive Transcranial Magnetic Stimulation, June 5-7, 1996. Electroencephalogr Clin Neurophysiol. 1998;108(1):1-16.

89. Zewdie E, Ciechanski P, Cherie Kuo HC, et al. Safety and tolerability of transcranial magnetic and direct current stimulation in children: prospective single center evidence from 3.5 million stimulations. Brain Stimulat. 2019;13(3). doi: 10.1016/j.brs.2019.12.025

90. Zaghi S, Acar M, Hultgren B, Boggio PS, Fregni F. Noninvasive brain stimulation with low-intensity electrical currents: putative mechanisms of action for direct and alternating current stimulation. Neuroscientist. 2010;16:285-307.

91. Nitsche MA, Paulus W. Excitability changes induced in the human motor cortex by weak transcranial direct current stimulation. J Physiol. 2000;527(Pt 3):633-39.

92. Dayan E, Censor N, Buch ER, Sandrini M, Cohen LG. Noninvasive brain stimulation: from physiology to network dynamics and back. Nat Neurosci. 2013;16:838. 
93. Bikson M, Grossman P, Thomas C, et al. Safety of transcranial direct current stimulation: evidence based update 2016. Brain Stimulat. 2016;9(5):641-61.

94. Fritsch B, Reis J, Martinowich K, et al. Direct current stimulation promotes BDNF-dependent synaptic plasticity: potential implications for motor learning. Neuron. 2010;66(2):198-204.

95. Reis J, Schambra HM, Cohen LG, et al. Noninvasive cortical stimulation enhances motor skill acquisition over multiple days through an effect on consolidation. Proc Natl Acad Sci USA. 2009;106(5):1590-95.

96. Elsner B, Kwakkel G, Kugler J, Mehrholz J. Transcranial direct current stimulation (tDCS) for improving capacity in activities and arm function after stroke: a network meta-analysis of randomised controlled trials. J Neuroengineering Rehabil. 2017;14(1):95.

97. Ciechanski P, Kirton A. Transcranial direct-current stimulation can enhance motor learning in children. Cereb Cortex. 2017;27(5):2758-67.

98. Kirton A, Ciechanski P, Zewdie E, et al. Transcranial direct current stimulation for children with perinatal stroke and hemiparesis. Neurology. 2017;88(3):259-67.

99. Gillick B, Rich T, Nemanich S, et al. Transcranial direct current stimulation and constraint-induced therapy in cerebral palsy: a randomized, blinded, sham-controlled clinical trial. Eur J Paediatr Neurol EJPN Off J Eur Paediatr Neurol Soc. 2018;22(3):358-68.

100. Kirton A, Deveber G, Pontigon A-M, Macgregor D, Shroff M. Presumed perinatal ischemic stroke: vascular classification predicts outcomes. Ann Neurol. 2008;63(4):436-43.

101. Broca P. Remarques sur le siége de la faculté du langage articulé, suivies d'une observation d'aphémie (parte de la parole). Bull Soc Anat Paris. 1861;6:330-57.

102. Wernicke C. Der aphasische Symptomencomplex. Berlin: Springer-Verlag; 1874.

103. Rorden C, Karnath H-O, Bonilha L. Improving lesion-symptom mapping. J Cogn Neurosci. 2007;19(7):1081-88.

104. Rorden C, Fridriksson J, Karnath H-O. An evaluation of traditional and novel tools for lesion behavior mapping. NeuroImage. 2009;44(4):1355-62.

105. Rorden C, Karnath H-O. Using human brain lesions to infer function: a relic from a past era in the fMRI age? Nat Rev Neurosci. 2004;5(10):813-19.

106. Boes AD, Prasad S, Liu H, et al. Network localization of neurological symptoms from focal brain lesions. Brain $\mathrm{J}$ Neurol. 2015;138(Pt 10):3061-75.

107. Gleichgerrcht E, Fridriksson J, Rorden C, Bonilha L. Connectomebased lesion-symptom mapping (CLSM): a novel approach to map neurological function. NeuroImage Clin. 2017;16:461-67.

108. Crichton A, Ditchfield M, Gwini S, et al. Brain magnetic resonance imaging is a predictor of bimanual performance and executive function in children with unilateral cerebral palsy. Dev Med Child Neurol. 2020;62(5):615-24.

109. Ferre CL, Carmel JB, Flamand VH, Gordon AM, Friel KM. Anatomical and functional characterization in children with unilateral cerebral palsy: an atlas-based analysis. Neurorehabil Neural Repair. 2020;34(2):148-58.

110. von Monakow C. Localization in the cerebrum and reduction of function by cortical foci. Wiesbaden; 1914.

111. Craig BT, Carlson HL, Kirton A. Thalamic diaschisis following perinatal stroke is associated with clinical disability. NeuroImage Clin. 2019;21:101660.

112. Craig BT, Olsen O, Mah S, et al. Crossed cerebellar atrophy in perinatal stroke. Stroke. 2019;50(1):175-77.

113. Li D, Hodge J, Wei X-C, Kirton A. Reduced ipsilesional cortical volumes in fetal periventricular venous infarction. Stroke. 2012;43(5):1404-7.

114. Luders E, Thompson PM, Narr KL, et al. A curvature-based approach to estimate local gyrification on the cortical surface. NeuroImage. 2006;29(4):1224-30.

115. White T, Su S, Schmidt M, Kao C-Y, Sapiro G. The development of gyrification in childhood and adolescence. Brain Cogn. 2010;72(1):36-45.

116. Wierenga LM, Langen M, Oranje B, Durston S. Unique developmental trajectories of cortical thickness and surface area. NeuroImage. 2014;87:120-26.
117. Oishi K, Faria AV, Yoshida S, Chang L, Mori S. Quantitative evaluation of brain development using anatomical MRI and diffusion tensor imaging. Int J Dev Neurosci. 2013;31(7): 512-24.

118. Stüber C, Morawski M, Schäfer A, et al. Myelin and iron concentration in the human brain: a quantitative study of MRI contrast. NeuroImage. 2014;93(Part 1):95-106.

119. Yu S, Carlson HL, Mineyko A, et al. Bihemispheric alterations in myelination in children following unilateral perinatal stroke. NeuroImage Clin. 2018;20:7-15.

120. Glasser MF, Van Essen DC. Mapping human cortical areas in vivo based on myelin content as revealed by T1- and T2weighted MRI. J Neurosci Off J Soc Neurosci. 2011;31(32): 11597-616.

121. Glasser MF, Goyal MS, Preuss TM, Raichle ME, Van Essen DC. Trends and properties of human cerebral cortex: correlations with cortical myelin content. NeuroImage. 2014;93(Pt 2):165-75.

122. Vandewouw MM, Young JM, Shroff MM, Taylor MJ, Sled JG. Altered myelin maturation in four year old children born very preterm. NeuroImage Clin. 2019;21:101635.

123. Lee S, Mirsky DM, Beslow LA, et al. Pathways for neuroimaging of neonatal stroke. Pediatr Neurol. 2017;69:37-48.

124. Barkovich AJ, Ferriero DM. Line-scan diffusion imaging of term neonates with perinatal brain ischemia. AJNR Am J Neuroradiol. 1999;20(9):1577-79.

125. Dudink J, Mercuri E, Al-Nakib L, et al. Evolution of unilateral perinatal arterial ischemic stroke on conventional and diffusionweighted MR imaging. AJNR Am J Neuroradiol. 2009;30(5): 998-1004.

126. Qiao M, Malisza KL, Del Bigio MR, Tuor UI. Transient hypoxiaischemia in rats: changes in diffusion-sensitive MR imaging findings, extracellular space, and $\mathrm{Na}^{+}-\mathrm{K}^{+}$- adenosine triphosphatase and cytochrome oxidase activity. Radiology. 2002;223(1):65-75.

127. Barber PA, Hoyte L, Kirk D, et al. Early T1- and T2-weighted MRI signatures of transient and permanent middle cerebral artery occlusion in a murine stroke model studied at 9.4T. Neurosci Lett. 2005;388(1):54-9.

128. Obenaus A, Ashwal S. Magnetic resonance imaging in cerebral ischemia: focus on neonates. Neuropharmacology. 2008; 55(3):271-80.

129. Beslow LA, Vossough A, Dahmoush HM, et al. Modified pediatric ASPECTS correlates with infarct volume in childhood arterial ischemic stroke. Front Neurol. 2012;3:122.

130. Rutherford M, Counsell S, Allsop J, et al. Diffusion-weighted magnetic resonance imaging in term perinatal brain injury: a comparison with site of lesion and time from birth. Pediatrics. 2004;114(4):1004-14.

131. De Vries LS, Van der Grond J, Van Haastert IC, Groenendaal F. Prediction of outcome in new-born infants with arterial ischaemic stroke using diffusion-weighted magnetic resonance imaging. Neuropediatrics. 2005;36(1):12-20.

132. Dudink J, Counsell SJ, Lequin MH, Govaert PP. DTI reveals network injury in perinatal stroke. Arch Dis Child Fetal Neonatal Ed. 2012;97(5):F362-64.

133. Koenraads Y, Porro GL, Braun KPJ, et al. Prediction of visual field defects in newborn infants with perinatal arterial ischemic stroke using early MRI and DTI-based tractography of the optic radiation. Eur J Paediatr Neurol EJPN Off J Eur Paediatr Neurol Soc. 2016;20(2):309-18.

134. Srivastava R, Rajapakse T, Carlson HL, et al. Diffusion imaging of cerebral diaschisis in neonatal arterial ischemic stroke. Pediatr Neurol. 2019;100:49-54.

135. Basser PJ, Pajevic S, Pierpaoli C, Duda J, Aldroubi A. In vivo fiber tractography using DT-MRI data. Magn Reson Med. 2000;44(4):625-32.

136. Basser PJ, Mattiello J, LeBihan D. MR diffusion tensor spectroscopy and imaging. Biophys J. 1994;66(1):259-67.

137. Basser PJ, Jones DK. Diffusion-tensor MRI: theory, experimental design and data analysis - a technical review. NMR Biomed. 2002;15:456-67.

138. Hodge J, Goodyear B, Carlson H, Wei X-C, Kirton A. Segmental diffusion properties of the corticospinal tract and motor outcome 
in hemiparetic children with perinatal stroke. J Child Neurol. 2017;32(6):550-59.

139. Kuczynski AM, Dukelow SP, Hodge JA, et al. Corticospinal tract diffusion properties and robotic visually guided reaching in children with hemiparetic cerebral palsy. Hum Brain Mapp. 2018;39(3):1130-44.

140. Fornito A, Zalesky A, Breakspear M. The connectomics of brain disorders. Nat Rev Neurosci. 2015;16(3):159-72.

141. Englander ZA, Pizoli CE, Batrachenko A, et al. Diffuse reduction of white matter connectivity in cerebral palsy with specific vulnerability of long range fiber tracts. NeuroImage Clin. 2013;2:440-47.

142. Ballester-Plané J, Schmidt R, Laporta-Hoyos O, et al. Whole-brain structural connectivity in dyskinetic cerebral palsy and its association with motor and cognitive function. Hum Brain Mapp. 2017;38(9):4594-612.

143. Englander ZA, Sun J, Case L, et al. Brain structural connectivity increases concurrent with functional improvement: evidence from diffusion tensor MRI in children with cerebral palsy during therapy. NeuroImage Clin. 2015;7:315-24.

144. Craig BT, Hilderley A, Kinney-Lang E, et al. Developmental neuroplasticity of the white-matter connectome in children with perinatal stroke. Neurology. 2020;95:1-11. doi:10.1212/WNL. 0000000000010669

145. Manning KY, Fehlings D, Mesterman R, et al. Resting state and diffusion neuroimaging predictors of clinical improvements following constraint-induced movement therapy in children with hemiplegic cerebral palsy. J Child Neurol. 2015;30(11):1507-14.

146. Rickards T, Sterling C, Taub E, et al. Diffusion tensor imaging study of the response to constraint-induced movement therapy of children with hemiparetic cerebral palsy and adults with chronic stroke. Arch Phys Med Rehabil. 2014;95(3):506-14.e1.

147. Zhang H, Schneider T, Wheeler-Kingshott CA, Alexander DC. NODDI: practical in vivo neurite orientation dispersion and density imaging of the human brain. NeuroImage. 2012;61(4):1000-16.

148. Nemanich ST, Mueller BA, Gillick BT. Neurite orientation dispersion and density imaging quantifies corticospinal tract microstructural organization in children with unilateral cerebral palsy. Hum Brain Mapp. 2019;40(17):4888-900.

149. Mackay A, Whittall $\mathrm{K}$, Adler J, et al. In vivo visualization of myelin water in brain by magnetic resonance. Magn Reson Med. 1994;31(6):673-77.

150. Manning AP, Chang KL, MacKay AL, Michal CA. The physical mechanism of "inhomogeneous" magnetization transfer MRI. J Magn Reson. 2017;274:125-36.

151. Deoni SCL, Rutt BK, Arun T, Pierpaoli C, Jones DK. Gleaning multicomponent $\mathrm{T} 1$ and $\mathrm{T} 2$ information from steady-state imaging data. Magn Reson Med. 2008;60(6):1372-87.

152. Stikov N, Campbell JSW, Stroh T, et al. In vivo histology of the myelin g-ratio with magnetic resonance imaging. NeuroImage. 2015;118:397-405.

153. Wintermark P, Warfield SK. New insights in perinatal arterial ischemic stroke by assessing brain perfusion. Transl Stroke Res. 2012;3(2):255-62.

154. Watson CG, Dehaes M, Gagoski BA, Grant PE, Rivkin MJ. Arterial spin labeling perfusion magnetic resonance imaging performed in acute perinatal stroke reveals hyperperfusion associated with ischemic injury. Stroke. 2016;47(6):1514-19.

155. De Vis JB, Petersen ET, Kersbergen KJ, et al. Evaluation of perinatal arterial ischemic stroke using noninvasive arterial spin labeling perfusion MRI. Pediatr Res. 2013;74(3):307-13.

156. Pienaar R, Paldino MJ, Madan N, et al. A quantitative method for correlating observations of decreased apparent diffusion coefficient with elevated cerebral blood perfusion in newborns presenting cerebral ischemic insults. NeuroImage. 2012;63(3):1510-18.

157. Lake EMR, Bazzigaluppi P, Stefanovic B. Functional magnetic resonance imaging in chronic ischaemic stroke. Philos Trans R Soc Lond B Biol Sci. 2016;371(1705):20150353.

158. Calautti C, Baron JC. Functional neuroimaging studies of motor recovery after stroke in adults: a review. Stroke. 2003;34(6):1553-66
159. Rehme AK, Eickhoff SB, Rottschy C, Fink GR, Grefkes C. Activation likelihood estimation meta-analysis of motor-related neural activity after stroke. NeuroImage. 2012;59(3):2771-82.

160. Gaberova K, Pacheva I, Ivanov I. Task-related fMRI in hemiplegic cerebral palsy - a systematic review. J Eval Clin Pract. 2018;24(4):839-850.

161. Biswal B, Yetkin FZ, Haughton VM, Hyde JS. Functional connectivity in the motor cortex of resting human brain using echoplanar MRI. Magn Reson Med. 1995;34(4):537-41.

162. Grayson DS, Fair DA. Development of large-scale functional networks from birth to adulthood: a guide to the neuroimaging literature. NeuroImage. 2017;160:15-31.

163. van den Heuvel MI, Turk E, Manning JH, et al. Hubs in the human fetal brain network. Dev Cogn Neurosci. 2018;30:108-15.

164. Fair DA, Cohen AL, Power JD, et al. Functional brain networks develop from a "local to distributed" organization. PLoS Comput Biol. 2009;5(5):e1000381

165. de Bie HMA, Boersma M, Adriaanse S, et al. Resting-state networks in awake five- to eight-year old children. Hum Brain Mapp. 2012;33(5):1189-201.

166. Vandermeeren Y, Sebire G, Grandin CB, et al. Functional reorganization of brain in children affected with congenital hemiplegia: fMRI study. NeuroImage. 2003;20(1):289-301.

167. Cao Y, Vikingstad EM, Huttenlocher PR, Towle VL, Levin DN. Functional magnetic resonance studies of the reorganization of the human hand sensorimotor area after unilateral brain injury in the perinatal period. Proc Natl Acad Sci USA. 1994; 91(20):9612-16.

168. Van de Winckel A, Klingels K, Bruyninckx F, et al. How does brain activation differ in children with unilateral cerebral palsy compared to typically developing children, during active and passive movements, and tactile stimulation? An fMRI study. Res Dev Disabil. 2013;34(1):183-97.

169. Wilke M, Staudt M, Juenger H, et al. Somatosensory system in two types of motor reorganization in congenital hemiparesis: topography and function. Hum Brain Mapp. 2009;30(3):776-88.

170. Guzzetta A, Bonanni P, Biagi L, et al. Reorganisation of the somatosensory system after early brain damage. Clin Neurophysiol Off J Int Fed Clin Neurophysiol. 2007;118(5):1110-21.

171. Weinstein M, Green D, Rudisch $\mathrm{J}$, et al. Understanding the relationship between brain and upper limb function in children with unilateral motor impairments: a multimodal approach. Eur J Paediatr Neurol. 2018;22:143-54.

172. Chu D, Huttenlocher PR, Levin DN, Towle VL. Reorganization of the hand somatosensory cortex following perinatal unilateral brain injury. Neuropediatrics. 2000;31(2):63-9.

173. Arichi T, Counsell SJ, Allievi AG, et al. The effects of hemorrhagic parenchymal infarction on the establishment of sensori-motor structural and functional connectivity in early infancy. Neuroradiology. 2014;56(11):985-94.

174. Gordon AL, Wood A, Tournier JD, Hunt RW. Corticospinal tract integrity and motor function following neonatal stroke: a case study. BMC Neurol. 2012;12:53.

175. van der Hoorn A, Potgieser ARE, Brouwer OF, de Jong BM. Compensatory cerebral motor control following presumed perinatal ischemic stroke. Eur J Paediatr Neurol. 2014; 18(6):793-95.

176. Dinomais M, Chinier E, Lignon $\mathrm{G}$, et al. The effect of videoguidance on passive movement in patients with cerebral palsy: fMRI study. Res Dev Disabil. 2013;34(10):3487-96.

177. Weinstein M, Green D, Geva R, et al. Interhemispheric and intrahemispheric connectivity and manual skills in children with unilateral cerebral palsy. Brain Struct Funct. 2014;219(3):1025-40.

178. Staudt M, Braun C, Gerloff C, et al. Developing somatosensory projections bypass periventricular brain lesions. Neurology. 2006;67:522-25.

179. Lemée J-M, Chinier E, Ali P, et al. (Re)organisation of the somatosensory system after early brain lesion: a lateralization index fMRI study. Ann Phys Rehabil Med. 2019. doi: 10.1016/j. rehab.2019.02.001

180. Juenger H, Grodd W, Krägeloh-Mann I, Staudt M. (Re-)organization of basal ganglia in congenital hemiparesis with ipsilateral cortico-spinal projections. Neuropediatrics. 2008;39(5):252-58. 
181. Hodics T, Cohen LG, Cramer SC. Functional imaging of intervention effects in stroke motor rehabilitation. Arch Phys Med Rehabil. 2006;87(12 Suppl 2):S36-42.

182. Johansen-Berg H, Dawes H, Guy C, et al. Correlation between motor improvements and altered fMRI activity after rehabilitative therapy. Brain. 2002;125:2731-42.

183. Liepert J, Bauder H, Wolfgang HR, et al. Treatment-induced cortical reorganization after stroke in humans. Stroke. 2000;31:1210-16.

184. Schaechter JD, Kraft E, Hilliard TS, et al. Motor recovery and cortical reorganization after constraint-induced movement therapy in stroke patients: a preliminary study. Neurorehabil Neural Repair. 2002;16:326-38.

185. Wittenberg GF, Chen R, Ishii K, et al. Constraint-induced therapy in stroke: magnetic-stimulation motor maps and cerebral activation. Neurorehabil Neural Repair. 2003;17:48-57.

186. Hamzei F, Liepert J, Dettmers C, Weiller C, Rijntjes M. Two different reorganization patterns after rehabilitative therapy: an exploratory study with fMRI and TMS. Neuroimage. 2006;31:710-20.

187. Liepert J. Motor cortex excitability in stroke before and after constraint-induced movement therapy. Cogn Behav Neurol. 2006;19(1):41-7.

188. Liepert J, Miltner WH, Bauder H, et al. Motor cortex plasticity during constraint-induced movement therapy in stroke patients. Neurosci Lett. 1998;250:5-8.

189. Sutcliffe TL, Gaetz WC, Logan WJ, Cheyne DO, Fehlings DL. Cortical reorganization after modified constraint-induced movement therapy in pediatric hemiplegic cerebral palsy. J Child Neurol. 2007;22:1281-87.

190. Juenger H, Kuhnke N, Braun C, et al. Two types of exerciseinduced neuroplasticity in congenital hemiparesis: a transcranial magnetic stimulation, functional MRI, and magnetoencephalography study. Dev Med Child Neurol. 2013;55:941-51.

191. Ilves $\mathrm{N}$, Ilves $\mathrm{P}$, Laugesaar $\mathrm{R}$, et al. Resting-state functional connectivity and cognitive impairment in children with perinatal stroke. Neural Plast. 2016;2016:2306406.

192. Manning KY, Fehlings D, Mesterman R, et al. Resting state and diffusion neuroimaging predictors of clinical improvements following constraint-induced movement therapy in children with hemiplegic cerebral palsy. J Child Neurol. 2015;30(11):1507-14.

193. Papadelis C, Ahtam B, Nazarova M, et al. Cortical somatosensory reorganization in children with spastic cerebral palsy: a multimodal neuroimaging study. Front Hum Neurosci. 2014;8:725.

194. Simon-Martinez C, Jaspers E, Alaerts K, et al. Influence of the corticospinal tract wiring pattern on sensorimotor functional connectivity and clinical correlates of upper limb function in unilateral cerebral palsy. Sci Rep. 2019;9(1):8230.

195. Qin Y, Sun B, Zhang H, et al. Aberrant interhemispheric functional organization in children with dyskinetic cerebral palsy. BioMed Res Int. 2019;2019:4362539.

196. Saunders J, Carlson HL, Cortese F, Goodyear BG, Kirton A. Imaging functional motor connectivity in hemiparetic children with perinatal stroke. Hum Brain Mapp. 2019;40(5):1632-42.

197. Woodward KE, Gaxiola-Valdez I, Goodyear BG, Federico P. Frontal lobe epilepsy alters functional connections within the brain's motor network: a resting-state fMRI study. Brain Connect. 2014;4(2):91-9.

198. Woodward KE, Carlson HL, Kuczynski A, et al. Sensory-motor network functional connectivity in children with unilateral cerebral palsy secondary to perinatal stroke. NeuroImage Clin. 2019;21:101670.

199. Staudt M, Lidzba K, Grodd W, et al. Right-hemispheric organization of language following early left-sided brain lesions: functional MRI topography. Neuroimage. 2002;16(10538119):954-67.

200. Holland SK, Vannest J, Mecoli M, et al. Functional MRI of language lateralization during development in children. Int $\mathrm{J}$ Audiol. 2007;46(9):533-51.

201. Jacola LM, Schapiro MB, Schmithorst VJ, et al. Functional magnetic resonance imaging reveals atypical language organization in children following perinatal left middle cerebral artery stroke. Neuropediatrics. 2006;37(1):46-52.
202. Tillema JM, Byars AW, Jacola LM, et al. Cortical reorganization of language functioning following perinatal left MCA stroke. Brain Lang. 2008;105(2):99-111.

203. Guzzetta A, Pecini C, Biagi L, et al. Language organisation in left perinatal stroke. Neuropediatrics. 2008;39(3):157-63.

204. Chilosi AM, Bulgheroni S, Turi M, et al. Hemispheric language organization after congenital left brain lesions: a comparison between functional transcranial Doppler and functional MRI. J Neuropsychol. 2019;13(1):46-66.

205. Ilves P, Tomberg T, Kepler J, et al. Different plasticity patterns of language function in children with perinatal and childhood stroke. J Child Neurol. 2014;29(6):756-64.

206. Raja Beharelle A, Dick AS, Josse G, et al. Left hemisphere regions are critical for language in the face of early left focal brain injury. Brain J Neurol. 2010;133(Pt 6):1707-16.

207. Szaflarski JP, Allendorfer JB, Byars AW, et al. Age at stroke determines post-stroke language lateralization. Restor Neurol Neurosci. 2014;32(6):733-42.

208. Booth JR, Macwhinney B, Thulborn KR, et al. Functional organization of activation patterns in children: whole brain fMRI imaging during three different cognitive tasks. Prog Neuropsychopharmacol Biol Psychiatry. 1999;23:669-82.

209. Ballantyne AO, Spilkin AM, Hesselink J, Trauner DA. Plasticity in the developing brain: intellectual, language and academic functions in children with ischaemic perinatal stroke. Brain. 2008;131:2975-85.

210. Dick AS, Raja Beharelle A, Solodkin A, Small SL. Interhemispheric functional connectivity following prenatal or perinatal brain injury predicts receptive language outcome. J Neurosci Off J Soc Neurosci. 2013;33(13):5612-25.

211. Carlson HL, Sugden C, Brooks BL, Kirton A. Functional connectivity of language networks after perinatal stroke. NeuroImage Clin. 2019;23:101861.

212. Rae CD. A guide to the metabolic pathways and function of metabolites observed in human brain $1 \mathrm{H}$ magnetic resonance spectra. Neurochem Res. 2014;39(1):1-36.

213. Carlson HL, MacMaster FP, Harris AD, Kirton A. Spectroscopic biomarkers of motor cortex developmental plasticity in hemiparetic children after perinatal stroke. Hum Brain Mapp. 2017;38(3):1574-87.

214. Kulak W, Sobaniec W, Smigielska-Kuzia J, et al. An age and gender dependency of metabolite concentrations in basal ganglia in children with spastic diplegia: proton magnetic resonance spectroscopy study. J Child Neurol. 2009; 24(1):73-9.

215. Kulak W, Sobaniec W, Kubas B, Walecki J. Proton magnetic resonance spectroscopy in children with spastic diplegia. Neurosci Lett. 2004;363(1):62-4.

216. Carlson HL, Ciechanski P, Harris AD, MacMaster FP, Kirton A. Changes in spectroscopic biomarkers after transcranial direct current stimulation in children with perinatal stroke. Brain Stimulat. 2018;11(1):94-103.

217. Auvichayapat P, Aree-Uea B, Auvichayapat N, et al. Transient changes in brain metabolites after transcranial direct current stimulation in spastic cerebral palsy: a pilot study. Front Neurol. 2017;8:366.

218. Poldrack RA, Huckins G, Varoquaux G. Establishment of best practices for evidence for prediction: a review. JAMA Psychiatry. 2019. doi: 10.1001/jamapsychiatry.2019.3671

219. Hollis A, Zewdie E, Nettel-Aguirre A, et al. Transcranial static magnetic field stimulation of the motor cortex in children. Front Neurosci. 2020;14:464.

220. Gillick BT, Kirton A, Carmel JB, Minhas P, Bikson M. Pediatric stroke and transcranial direct current stimulation: methods for rational individualized dose optimization. Front Hum Neurosci. 2014;8:739.

221. Ciechanski P, Carlson HL, Yu SS, Kirton A. Modeling transcranial direct-current stimulation-induced electric fields in children and adults. Front Hum Neurosci. 2018;12:268.

222. Datta A, Truong D, Minhas P, Parra LC, Bikson M. Interindividual variation during transcranial direct current stimulation and normalization of dose using MRI-derived computational models. Front Psychiatry. 2012;3:91. 